\title{
Análisis político-institucional del sistema de gestión regional: el caso de la región de Tarapacá en Chile*
}

\author{
Pablo Monje Reyes** \\ Marcela Ferrer Lues*** \\ Antonieta Surawski Cisternas****
}

SuMARIO: 1. Presentación; 2. Descripción del estudio; 3 . Enfoque teórico para el análisis político-institucional del sistema de gestión regional; 4. Análisis político-institucional del sistema de gestión regional de Tarapacá; 5. Conclusiones.

Aв STRACT: 1. Introduction; 2. The study; 3 . Theoretical approach to the political-institutional analysis of the regional management system; 4. Political-institutional analysis of Tarapacá's regional management system; 5. Conclusions.

PALABRAS CLAVES: gestión regional; actores; liderazgo; redes; instituciones; articulación; coordinación; integración; modelo; inversión; análisis.

\footnotetext{
* Artículo recibido en mar. y aceptado en nov. 2006. Esta publicación presenta los resultados del estudio "Análisis del Sistema de Gestión Regional". El estudio fue encargado por la División Regional de la Subsecretaría de Desarrollo Regional y Administrativo (Subdere) al Instituto de Asuntos Públicos de la Universidad de Chile.

** Administrador público, Universidad de Los Lagos, Magíster en Gestión y Políticas Públicas, Universidad de Chile, profesor asistente del Departamento de Gobierno y Gestión Pública del Instituto de Asuntos Públicos de la Universidad de Chile, investigador asociado al Consejo Latinoamericano de Ciencias Sociales (Clacso). Dirección: Santa Lucia, 240 - Santiago Centro — Santiago — Chile. E-mail: pmonje@uchile.cl.

*** Socióloga, Universidad de Chile, Master of Health Science, University of Toronto, diploma en Población y Desarrollo (Cepal/Celade), profesora asistente, Facultad de Ciencias Sociales de la Universidad de Chile. Dirección: Santa Lucia, 240 - Santiago Centro - Santiago - Chile. E-mail: maferrer@uchile.cl.

**** Licenciada en arquitectura. Universidad de Valparaíso, Chile, Master en Estudios del Medio Ambiente (Planificación Urbana y Regional) York University, Toronto, Canadá. Dirección: Santa Lucia, 240 - Santiago Centro — Santiago — Chile. E-mail: surawski@uchile.cl.
} 
KEY WORDS: regional management; actors; leadership; networks; institutions; articulation; coordination; integration; model; investment; analysis.

Este artículo tiene como objetivo central analizar, describir y elaborar propuestas en el ámbito del mejoramiento de los procesos y mecanismos político-institucionales del sistema de gestión regional, incluyendo los niveles regional, provincial y comunal. El objetivo se orienta a reconstruir y analizar el proceso de implementación del modelo de gestión regional, considerando las relaciones que establece con los distintos actores involucrados a lo largo de dicho proceso y sus resultados, desde la priorización comunal hasta la regional. Se trata, fundamentalmente, de un análisis del proceso social de toma de decisiones de inversión territorial, del rol que asumen los distintos actores en los distintos niveles, de las relaciones que establecen entre ellos, y de los factores que facilitan y obstaculizan el proceso y sus resultados. El análisis supone relaciones humanas en un marco institucional, que el interés radica en contrastar el diseño teórico del proceso con la realidad de su implementación, y que la participación de los actores en dicho proceso está mediatizada por su conciencia interna y realidad simbólica.

Political-institutional analysis of the regional management system: the case of the Tarapacá region in Chile

The main objective of this article is to analyze, describe and develop proposals for to the improvement of the political-institutional processes and mechanisms of the regional management system, including the regional, provincial and local levels. The objective is to reconstruct and analyze the process of implementing the regional management model, considering the relations that it establishes with the different actors involved throughout the process and its results, from local to regional prioritization. Basically, it analyzes the social process of decision making on territorial investments, the role of the different actors at the different levels, the relationship that they establish among themselves, and the factors that facilitate or obstruct the process and its results. This study focuses on human relationships in a institutional landmark, and the analysis contrasts the theoretical design with the actual implementation of the process and considers that the actors' participation is mediated by their inner conscience and their symbolic reality. 


\section{Presentación}

Este artículo presenta los resultados del estudio análisis político-institucional del sistema de gestión regional. El estudio fue encargado por la División Regional de la Subsecretaría de Desarrollo Regional y Administrativo (Subdere) al Instituto de Asuntos Públicos de la Universidad de Chile.

El informe se basa en el análisis de entrevistas semi-estructuradas realizadas a actores clave del ámbito comunal, provincial y regional de la región de Atacama. El análisis revela un modelo en proceso de articulación de la región de Atacama. Sin duda, esto es una muestra de la diversidad territorial de los modelos de gestión que se aplican en las diversas regiones del país, aunque no agota la capacidad de diferenciación con otros modelos que se pueden estar implementando. La reflexión y análisis de estos modelos ha permitido profundizar en estas características, posibilitando el desarrollo de potenciamiento, redefinición o redireccionamiento de los modelos de gestión regional en el nivel territorial. Es posible identificar los elementos comunes y las variables desencadenantes para fortalecer y o rediseñar el proceso de gestión regional, cuya implementación asumirá dimensiones particulares en cada una de las regiones del país.

El artículo presenta y discute los hallazgos observados en la región analizada, comprendiendo los componentes político e institucional del sistema, desde la perspectiva de los propios actores participantes. Se presenta las conclusiones que emanan del análisis.

\section{Descripción del estudio}

\section{Objetivo y metodología}

El objetivo de este estudio de caso es describir y realizar propuestas en el ámbito del mejoramiento de los procesos y mecanismos político-institucionales del sistema de gestión regional, incluyendo los niveles regional, provincial y comunal.

Como se observa, el objetivo se orienta a reconstruir y analizar el proceso de implementación del modelo de gestión regional, considerando las relaciones que establece con los distintos actores involucrados a lo largo de dicho proceso y sus resultados, desde la priorización comunal hasta la regional. Se trata, fundamentalmente, de un análisis del proceso social de toma de decisiones de inversión territorial, del rol que asumen los distintos actores en los distintos niveles, de las relaciones que establecen entre ellos, y de los factores que facilitan y obstaculizan el proceso y sus resultados. 
Considerando que el estudio supone un análisis de relaciones humanas en un marco institucional, que el interés radica en contrastar el diseño teórico del proceso con la realidad de su implementación, y que la participación de los actores en dicho proceso está mediatizada por su conciencia interna y realidad simbólica, se utilizó una estrategia cualitativa que permitiera reconstruir las modalidades que ha asumido dicho proceso, profundizando en el tipo y grado de relación establecida con los distintos actores, sus resultados, y los factores que facilitan y obstaculizan el proceso, desde la perspectiva de los propios actores. Para ello se realizaron entrevistas semi-estructuradas a los actores relevantes del proceso, identificados como informantes clave.

El estudio fue realizado en las regiones de Atacama, Bío Bío, Aysén y Metropolitana, en el entendido de tratar de representar, aunque no agotar, la diversidad existente a lo largo del país. En esta publicación se presentan los resultados del análisis de la región de Atacama.

Se entrevistó a actores políticos y técnicos en el nivel comunal, provincial y regional, los que fueron considerados como informantes claves del proceso. Para ello, se utilizó una pauta de entrevista que permitiera reconstruir el proceso de toma de decisiones, desde la perspectiva de los propios actores. La pauta fue adecuada a cada actor/realidad específica durante la aplicación de la entrevista.

\section{Consideraciones éticas de estudio}

Este estudio tuvo como objetivo central analizar el modelo de gestión regional. Aunque no se realizó una evaluación del proceso, es probable que las personas entrevistadas percibieran este estudio como una evaluación de su desempeño en los distintos niveles. Tales personas tienen distintas responsabilidades en el proceso y una serie de relaciones jerárquicas entre sí. Esto dificulta el proceso de recolección de la información, lo que puede agravarse cuando el número de actores es relativamente pequeño y es factible identificar a cada actor incluso si se omite su nombre, utilizando criterios de fácil acceso como es la pertenencia institucional. También puede agravarse si la entrevista se considera una actividad laboral más, que recarga su agenda de trabajo.

Además de constituir una limitación que puede incidir en la calidad y validez de la información recolectada, la situación descrita en el párrafo anterior exige atender a una serie de consideraciones éticas, orientadas a proteger tanto las relaciones entre las distintas personas entrevistadas (que seguirán trabajando juntas, algunas en relaciones de dependencia o subordinación), como también la calidad de la información. Las consideraciones fueron las siguientes: 
口 los entrevistados fueron claramente informados respecto de las características generales del estudio y sus objetivos. Se insistió en que la idea es obtener información para mejorar el proceso;

口 se solicitó a los entrevistados su consentimiento para grabar la entrevista, indicándole que puede solicitar detener la grabación en cualquier momento. Las cintas han sido guardadas por el equipo de investigación;

口 cuando se utilizaron citas textuales, se omitieron los nombres y se realizó el mayor esfuerzo por omitir cualquier información que permitiera identificar a la persona que emitió esa opinión.

\section{Análisis de la información}

Con base en la información recolectada se reconstruyó el modelo de gestión regional, el rol de los distintos actores en las distintas etapas del proceso, las relaciones y modalidades de trabajo establecidas entre los actores en los distintos niveles, los factores que favorecen u obstaculizan estas relaciones y la contribución de los instrumentos y metodologías existentes para potenciar el proceso, desde la perspectiva de los propios actores. El análisis consideró las semejanzas y diferencias entre las visiones de los distintos actores, tratando de encontrar las oportunidades y nudos críticos del trabajo conjunto de los distintos actores, de acuerdo a sus pertenencias institucionales.

Los casos regionales fueron analizados individualmente. El análisis se realizó en los niveles comunal, provincial y regional, incluyendo también un análisis transversal de estos tres niveles.

\section{Enfoque teórico para el análisis político-institucional del sistema de gestión regional}

El sistema de gestión regional es una construcción conciente de un sistema abierto, formado por un componente político y otro institucional o tecnoadministrativo, que construye relaciones complejas tanto intra como extra organizacionales (Peters, 1999). Desde el componente político, el sistema tiene una estructura de decisiones liderada por actores institucionales regionales, definidos políticamente: el intendente, como ejecutivo regional, y el Consejo Regional (Core), como órgano resolutivo y fiscalizador, expresión de la participación política indirecta de la comunidad regional.

Desde el componente institucional, el sistema posee una estructura "pertinente" para su funcionamiento y logro de objetivos, que es determinada 
por la ley. ${ }^{1}$ Esta estructura está racionalmente construida y su objetivo central es buscar el desarrollo de una región en las siguientes áreas: ordenamiento territorial; fomento de actividades productivas; desarrollo social y cultural. Para el cumplimiento de sus funciones y objetivos, la ley le otorga al sistema las atribuciones necesarias e indispensables, como también define una planta de personal y recursos financieros para su operación. En síntesis, estamos frente a un sistema de gestión regional integrado por competencias y recursos, con un componente político y uno institucional, cuya principal característica es estar abierto al medio regional o a su ámbito de acción territorial concreto.

\section{El componente político del sistema de gestión regional}

Entendemos el componente político como una parte de la estructura del sistema de gestión regional, en el cual se configura el espacio de las decisiones político-administrativas de la región. En este espacio confluyen los actores regionales, provinciales y comunales, para organizar y ejecutar los procesos de decisión. El estudio indaga sobre las siguientes dimensiones: articulación y coordinación administrativa de los actores; capacidad política de los actores; confianza entre los actores y en el sistema; y participación.

\section{ARTICULACIÓN Y COORDINACIÓN POLÍTICO-ADMINISTRATIVA DE LOS ACTORES}

El sistema de gestión contempla la articulación y coordinación de los actores de las diferentes unidades territoriales político-administrativas y los sectores específicos. Esto se manifiesta en términos inter-territoriales (articulación vertical), intra-territoriales (articulación horizontal), inter-sectoriales (articulación sectorial), e intra-inter sectorial-territorial (articulación territorio-sector). El estudio analiza el grado en que se implementan estas distintas articulaciones, como también los facilitadores y obstaculizadores de dichos procesos.

Articulación vertical. Es la capacidad de realizar el alineamiento vertical e integrar y ajustar las organizaciones a los programas (Marini y Martins, 2004) con los cuales se relacionan las distintas estructuras político-administrativas de una región. La articulación vertical es, esencialmente, una tarea de conciliación y convergencia de agenda. Con esto se busca coordinar esfuerzos

\footnotetext{
${ }^{1}$ Para analizar en profundidad la estructura y funciones del sistema de gestión regional véase Ley ${ }^{\circ} 19.175$, Orgánica Constitucional sobre Gobierno y Administración Regional, y la Ley ${ }^{\circ}$ 19.379 que fija las Plantas de Personal de los Servicios Administrativos de los Gobiernos Regionales.
} 
de las distintas estructuras político-administrativas territoriales en la búsqueda de resultados comunes.

La articulación vertical se orienta a estructurar objetivos de desarrollo concertados entre las distintas unidades territoriales presentes en una región, lo que requiere de ajustes en los modelos de gestión regional, en términos de estrategias de desarrollo, estructuras, procesos, perfil del cuadro funcional y sistema de información (Marini y Martins, 2004). Esta articulación pretende coordinar el proceso de toma de decisiones principalmente por ajustes mutuos, y tiene gran énfasis en el uso de dispositivos de enlace (Mintzberg, 1991).

Articulación horizontal. Implica articular las diversas organizaciones que implementan políticas de desarrollo en una misma unidad territorial político-administrativa de la región. Trata de establecer, para cada política, una red de organizaciones circunscritas a ella en su implementación (Marini y Martins, 2004). Complementariamente, se puede afirmar que esta articulación no descansa en la distribución de poder por la línea de mando de la estructura de gestión. Corresponde más bien a una coordinación de órganos con distintas funciones de poder en la estructura superior de decisiones, como ocurre entre un órgano ejecutivo y uno de decisión o cuerpo colegiado (Mintzberg, 1991). Por tanto, podemos encontrar estas articulaciones entre ejecutivo regional Consejo Regional a nivel de la región, y/o alcalde - Concejo Comunal a nivel local, como también entre municipios.

Articulación intersectorial. Es aquella coordinación y cooperación que se espera ocurra entre los distintos sectores que, si bien tienen un ámbito de acción específico, comparten un público objetivo común y/o un territorio. La intersectorialidad está asociada a una gran consistencia lógica y operacional de las acciones de desarrollo, entre diversas entidades involucradas en las mismas zonas territoriales. Busca desarrollar una visión intersectorial sobre acciones desarrollo, que tiene impacto sobre un territorio determinado y beneficiarios comunes.

Articulación sectorial-territorial. Es la coordinación, integración y convergencia que ocurre entre los sectores que gestionan políticas de desarrollo de una misma cartera (por ejemplo, SAG, Indap y Conaf, todas pertenecientes al Ministerio de Agricultura), y las distintas unidades políticas administrativas territoriales, a saber, gobierno regional, gobernación provincial y municipio. Esta articulación se refiere a cómo los sectores se coordinan e integran con los territorios específicos, y cómo estos últimos orientan sus esfuerzos de articulación en el mismo sentido. Trata de evitar la fragmentación sectorial de las políticas públicas con impacto territorial. Su principal estrategia es reconocer los mecanismos causales de la fragmentación (Martins, 2004), para posteriormente proceder al desarrollo de mecanismos de coordinación, integración y convergencia de los sectores. Es posible implementar también esa estrategia para mejorar los procesos de articulación intersectorial. 


\section{Capacidad política de los actores}

La capacidad política de los actores refiere a los conocimientos, habilidades y competencias que les permite visualizar y potenciar distintas herramientas políticas y de gestión para la implementación del modelo de gestión. El estudio analiza tres ámbitos principales: capacidad de generación y articulación de redes; influencia sobre las decisiones tanto en el proceso como resultado final; y liderazgo.

Capacidad para la generación y articulación de redes. Es la capacidad que tienen los gestores y líderes regionales y locales de emprender la creación y articulación de redes de gestión para el logro de sus objetivos de desarrollo, en el plano territorial en el cual se desenvuelven. El concepto de redes corresponde a un nudo de relaciones entre actores que se benefician al pertenecer a ellas (Muñoz, 1997; Castells, 1999), que se hacen presentes en el hecho que concentran su atención en las interacciones existentes entre las estructuras territoriales, políticas y grupos de interés privado (Peters, 1999). Estas interrelaciones son importantes, ya que aumentan la información de los actores del proceso de decisión.

Las redes suponen cooperación y capacidad de acuerdo entre los actores tanto durante el proceso, como en la toma de decisiones finales (Putnam, 1994). No obstante, la generación de redes no garantiza la ausencia de conflicto. Por el contrario, es posible encontrar acciones de contraposición entre una o más redes sobre un mismo eje de desarrollo. Por ejemplo, el caso de los cisnes en el Santuario del Río Cruces en Valdivia. Por un lado se observan las acciones de presión de la comunidad Valdiviana organizada. Por otro, las acciones de la empresa sindicada como responsable del daño ambiental.

Influencia sobre las decisiones. Se puede definir como la capacidad de los actores de realizar acciones en las cuales se potencia el desarrollo de una idea, de un objetivo o de un beneficio, es decir, "lograr que una persona distinta a uno, haga por uno lo que uno desea" (Bobbio et al., 1999), para la comunidad o área territorial. Representa la capacidad de los actores para influir tanto en el proceso como en el resultado final. Claramente, esto se concatena con la capacidad de generar y articular redes que contengan en si mismas la capacidad influir en las decisiones de los actores.

Liderazgo. Lo entendemos como la capacidad propia de una persona o de una institución para conducir, coordinar e integrar a otros a un proceso de decisión. Utilizaremos la tipificación weberania de liderazgo desde la perspectiva de las fuentes de legitimidad: el poder legal, propio de los estados burocráticos, con leyes que mandan, permiten o prohíben, donde tales mandatos estarían por encima de los individuos que los ejercen; el poder tradicional, basado en caracteres sacros o en una autoridad heredada y/o patriarcal que por principio no se cuestiona; y el poder carismático, basado en una situación 
casi afectiva a la persona de un jefe, que descansa en sus aptitudes y características de personalidad individual (Weber, 1997).

\section{Confianza}

Un elemento clave para el funcionamiento del sistema de gestión regional es la confianza, tanto entre los actores, como de los actores en el sistema (confianza en sí y confianza para sí). El estudio indaga la percepción de los actores respecto de la existencia de confianza, como también de los facilitadores y obstaculizadores de ella.

La confianza es un elemento intangible que se produce entre los actores. Significa que un actor cree en las acciones de otro actor, en términos de los resultados esperados por el primero. Significa también la capacidad de un actor para creer y reaccionar frente a los argumentos que esgrime otro, y cambiar sus posiciones en pro de un resultado tangible y racionalmente esperable (Putnam, 1994). La confianza se fortalece entre los actores cuando los resultados han sido producto de un proceso transparente y normado, lo que le otorga legitimidad al sistema de gestión. Se debilita cuando los resultados están sujetos a procesos poco normados y los actores perciben arbitrariedad en el proceso, como también en las decisiones que responde a la autoridad legal o que tienen excesiva permeabilidad de los grupos de presión. Como resultado, pierden legitimidad los procedimientos, los resultados y finalmente, el sistema de gestión en su globalidad. Pasamos entonces a un proceso inverso, de desconfianza y de desarticulación del sistema de gestión, porque los actores permanentemente lo critican y deslegitiman.

\section{Participación}

Entendemos participación, en términos generales, como la acción colectiva de los actores sociales e institucionales de integrarse, proponer, controlar y evaluar críticamente los procesos de decisión pública (Lechner, 1991; Zimmerman, 1992; Mouffe, 1992; Cunill, 1997; Bobbio et al., 1999), en las esferas territoriales específicas. El estudio indaga los niveles de participación como también la visión de los actores al respecto, en dos ámbitos: participación institucional y participación de las organizaciones sociales y políticas.

Participación institucional. Es la acción colectiva de las instituciones regionales, provinciales y comunales en participar en el proceso y la toma de decisiones finales. Se caracteriza principalmente por la capacidad institucional del sistema de gestión de convocar, solicitar y articular la participación de los sectores y servicios en decisiones públicas que tienen impacto territorial. 
Participación de las organizaciones sociales y políticas. Es la acción colectiva de las distintas organizaciones sociales y políticas de integrarse, proponer, controlar y evaluar críticamente los procesos de decisión pública (Lechner, 1991; Zimmerman, 1992; Mouffe, 1992; Cunill, 1997; Bobbio et al., 1999) sobre cuestiones que son importantes para ellos (Held, 1993). Se expresa en términos de intervención directa o delegada en las decisiones de política pública. En nuestra realidad institucional, la participación de las organizaciones sociales y políticas está determinada por los espacios y canales de deliberación colectiva a nivel regional, provincial y local.

\section{El componente institucional del sistema de gestión regional}

Entendemos la dimensión institucional como la otra parte del sistema de gestión regional, en la cual se apoya la estructura decisional político-administrativa, por medio de la utilización de las normas y de los instrumentos de planificación y gestión, léase Estrategia Regional de Desarrollo (ERD); Presupuesto Regional; Sistema Nacional de Inversiones (SNI), entre otros. Este componente no será desarrollado en este trabajo solo por razones de espacio.

\section{Conocimiento y aplicación de normas e instrumentos}

El estudio aborda la capacidad técnica de los actores tanto en el conocimiento de normas e instrumentos, como su utilización para la gestión. Busca observar las particularidades de la utilización y entendimiento de esta dimensión, con el fin de entender la importancia relativa que le dan los actores a esta parte de la estructura de sistema de gestión regional. Específicamente, se indaga sobre la construcción de poder racional-legal (Weber, 1997) del sistema de gestión regional. Por tanto, se observa la percepción de los actores en el uso de las normas legales que sustentan el aparato político-administrativo de gestión. Se analiza la percepción respecto de la aplicabilidad y utilidad de la legislación y la normativa vigente. La idea central es visualizar cómo los actores se refieren a la utilidad de la normativa vigente vinculada al logro de sus objetivos y funciones. Es también entender cuál es el valor crítico que le dan a la normativa y si esta les permite ordenar y mejorar sus procesos de gestión regional. Para ello, se examina la utilización de la legislación y normativa vigente en sus aspectos tecno-administrativos, como también el manejo conceptual de los actores institucionales del sistema de gestión.

En cuanto a los instrumentos de gestión, se indaga sobre la percepción de uso de las herramientas de planificación y gestión regional y como de 
programación de inversiones establecidos por la normativa vigente en las distintas unidades territoriales a saber; la región, provincia o comuna. Por último, se analiza la capacidad de creación y utilización de otros instrumentos legales para el funcionamiento del sistema de gestión regional, en particular, si se han creado algún tipo de reglamento que sustente las herramientas que se han desarrollado en la misma región.

\section{Particularidades del modelo}

Desde la perspectiva sistémico estructural-funcionalista (Parsons, 1966), se indaga sobre como el sistema de gestión de cada una de las regiones estudiadas tiene sus particularidades que la diferencia de otras regiones, a partir de la percepción y manejo de los actores de su propio sistema y su capacidad de comparación con respecto a otras regiones. Esto incide en las posibilidades y formas de institucionalización del sistema.

El siguiente esquema (figura 1) resume el sistema de gestión regional:

Figura 1

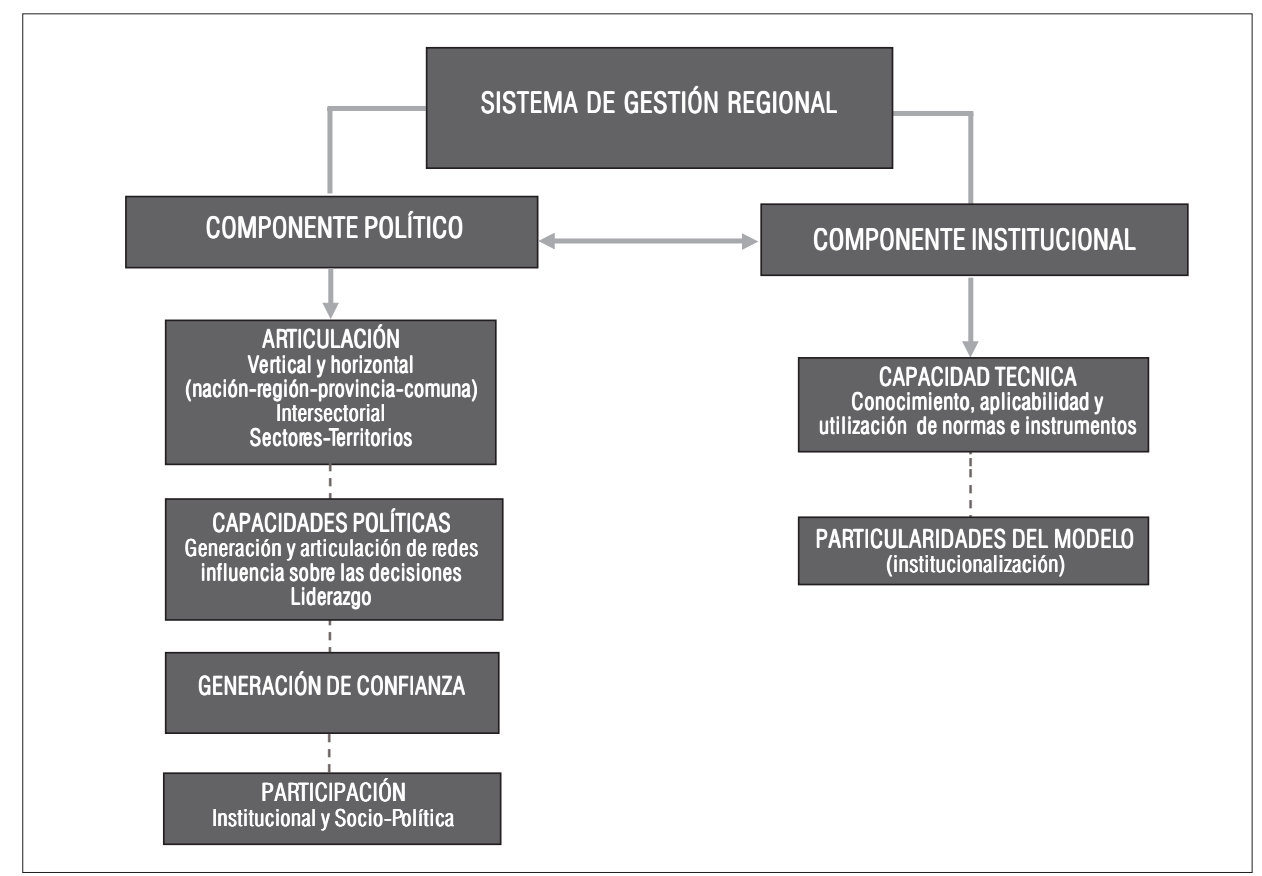




\section{Análisis político-institucional del sistema de gestión regional de Tarapacá}

\section{Componente político del sistema de gestión regional}

El componente político es una parte de la estructura del sistema de gestión regional, que configura el espacio de las decisiones político-administrativas de la región. En este espacio confluyen los actores regionales, provinciales y comunales, para organizar y ejecutar los procesos de decisión. Se indagó sobre las siguientes dimensiones: articulación y coordinación administrativa de los actores; capacidad política de los actores; confianza entre los actores y en el sistema; y participación.

\section{Articulación y coordinación político administrativa de los actores}

Articulación vertical. El estudio encontró que, en general, los actores dan cuenta de la existencia de algún tipo de integración espacial político administrativa entre la región, las provincias y las comunas. La relación con el país no aparece como significativa. Las visiones sobre la articulación presentan algunas diferencias en los distintos niveles.

En el nivel político regional, la articulación vertical es visualizada como un eje región-comuna, donde los gobernadores tienen un rol articulador de impacto limitado, puesto que su ámbito de acción está sujeto a las acciones del Gore y, concretamente, a las decisiones del intendente. El eje región-comuna se entiende como conciliador de los intereses de la región con los de la comuna, teniendo como foco la primera. Esta visión se ajusta al diseño del sistema de gestión regional y a las atribuciones que la ley le otorga al intendente. Al parecer, se ajusta también a las expectativas de los actores regionales políticos, puesto que ningún actor manifestó críticas negativas. La opinión de uno de ellos ilustra esta posición, enfatizando que es un proceso piramidal, donde el intendente toma las decisiones finales.

El eje región-comuna tiende a plantearse como una relación unidireccional liderada por la región. La provincia, cuando es reconocida, tiende a ser vista como una instancia intermedia supeditada en última instancia a la región.

A nivel provincial, mirado más bien como si fueran autoridades regionales, de la pertinencia estratégica o política de tal o cual iniciativa, a nivel de 
gobernación, yo diría que gobernación e Intendencia constituyen los actores más relevantes en esta validación o priorización política-estratégica.

Región de Atacama - político

A pesar de plantearse como una instancia intermedia supeditada a la región, el eje región-comuna puede verse interferido por las atribuciones de la provincia, ya sea por la acción de los gobernadores o de los consejeros regionales, cuando actúan directamente en las provincias que representan. La conexión con las provincias, que en principio es vista como positiva para la generación de propuestas provinciales, obstaculizaría luego el proceso de priorización regional, pues los consejeros tenderían a mantener la visión de la provincia por sobre la visión de la región. Desde esta perspectiva, la idea es estimular una visión global que recoja los intereses de la región.

Por otra parte, algunos actores piensan que el diseño del sistema es poco clarificador respecto del rol de las gobernaciones, o incluso obstaculiza el desempeño adecuado de ellas. Las funciones y dependencias territoriales-administrativas que la ley define para el Gore y la gobernación afectan negativamente la coordinación entre ambos:

la gobernación provincial depende del gobierno interior, las coordinaciones territoriales del gobierno regional, entonces son dos figuras que quizás, cuesta digamos, hacerlas coincidir. Bueno, yo creo que en lo formal, eso ha operado, y uno puede ver los documentos y obviamente va a estar expresado así, pero creo que los gobernadores tienen un problema por el lado de que los coordinadores territoriales, el Gore efectivamente, valga la redundancia, se coordinen efectivamente con ellos como gobernadores.

Las gobernaciones no sólo tienen dificultades para coordinarse con el Gore, sino también para coordinarse con los sectores. En esto incidirían factores relacionados con la cultura de trabajo de los sectores, los que tienen un foco en el nivel central más que regional, y muchos menos en relación con los niveles provincial y comunal. De esta forma, el rol de las gobernaciones sigue siendo una formalidad.

Las dificultades de articulación gobernación-Gore impactan también en la articulación gobernación-municipios, puesto que los municipios se contactan con las gobernaciones a través de los coordinadores territoriales, que dependen del Gore. Se reconoce la conexión directa municipio-Gore, a través de los coordinadores territoriales, dejando a los gobernadores con una mínima ingerencia en el proceso. 
Al igual que en el nivel regional político, en el nivel regional técnico prima la visión de un eje región-comuna. Sin embargo, en este nivel se le otorga a las gobernaciones provinciales un rol intermedio más activo. La articulación se da sostenidamente con las provincias de Chañaral y Huasco, siendo inexistente con la provincia de Copiapó.

La escasa participación de la provincia de Copiapó responde a su condición de cabecera regional, lo que hace que muchas veces sus funciones sean sobrepasadas por el Gore. Esto es reconocido también en el nivel provincial. A juicio de un actor político de la provincia de Copiapó, se necesita una mayor definición de ámbitos de competencia de la gobernación y el Gore, puesto que se tiende a duplicar funciones con la unidad de control de la intendencia. De hecho, el mismo actor señala que esta unidad lleva el trabajo técnico del proceso de priorización y que la metodología de priorización utiliza criterios de política regional, en especial la EDR y los resultados del taller de autoridades políticas del Gore. Es importante señalar, también, que el actor provincial reconoce que la gobernación carece de personal calificado suficiente para tener una participación más activa. Evidentemente, esto atenta contra la institucionalización del sistema de gestión regional y se refuerza por el hecho de que el Instructivo Presidencial no 155 entrega atribuciones, pero no recursos.

En el nivel comunal político existe consenso en que la comuna de Caldera tiene una escasa o nula relación con la provincia de Copiapó:

Mira, sinceramente, nosotros no tenemos mucha relación con el gobierno provincial, lo que hemos tenido es con el gobernador provincial hemos tenido alguna relación pero cuando ha sido intendente subrogante (...).

Comuna de Caldera - político

La relación provincia-comuna es reemplaza por la relación intendenciacomuna. La gobernación es absorbida por la Intendencia, puesto que ambas se encuentran en el mismo lugar:

la gobernación, que esté junto con la Intendencia para nosotros es un despropósito, nosotros nos relacionamos directamente con la intendencia porque está en Copiapó, pero que la gobernación provincial también esté en Copiapó, (...), porque la gestión la hace toda la intendencia, entonces al final es una figura que queda ahí pero sin hacer mucho.

Comuna de Caldera - político

Se otorga importancia a la articulación del municipio con el intendente y el Gore. Este tipo de articulación se ha fortalecido en el último tiempo, y ha sido estimulada por ambas partes. 
Además de la articulación con el Gore, se enfatiza la importancia de que el municipio se articule con el Core y con los profesionales de Serplac. La articulación del municipio con la gobernación no es mencionada.

La nula vinculación del municipio con la gobernación se ratifica en el nivel comunal técnico. En este nivel, se reconoce que la gobernación no desempeña ningún rol.

Claro, yo te diría que se salta eso, estamos en este municipio acá, se salta, estamos, vamos directamente, y si se da hablamos con la intendencia, ya cuando las cosas son muy inmediato, son muy urgentes, pero no, hay, hay ese salto, no pasa primero que nosotros, hablemos con la gobernación y que la gobernación se encargue de transmitirla a la intendencia, eso no ocurre.

$$
\text { Comuna de Caldera — técnico }
$$

Se señala que este esquema cambiará durante el año 2005. Sin embargo, este cambio se entiende como la agregación de un nivel más dentro de la escala formal de transmisión de los proyectos hacia la Intendencia, y no como una acción de coordinación entre los actores de la comuna, y menos de coordinación territorial entre las comunas que conforman la Provincia.

En síntesis, en los distintos niveles se observa coincidencia respecto de que existe algún tipo de integración espacial político-administrativa entre la región, las provincias y las comunas, dejando fuera el rol de la nación. Sin embargo, se observan algunos matices entre estas visiones. En el nivel regional político, la articulación es percibida como un eje región-comuna, donde los gobernadores tienen algún rol articulador, si bien su ámbito de acción está sujeto a las acciones del Gore y las decisiones del intendente. El eje regióncomuna se entiende como conciliador de los intereses de la región con los de la comuna, teniendo a la región como territorio determinante. Esto puede verse dificultado por las atribuciones de los niveles intermedios, ya sea los gobernadores o los consejeros regionales. En otras palabras, la articulación provincia-comuna es vista como positiva en sus etapas iniciales, pero luego es vista como un obstáculo, cuando se mantiene la visión de la provincia por sobre la visión de la región.

Por su parte, en el nivel regional técnico se visualiza también el eje regióncomuna, otorgándole a las gobernaciones provinciales un rol intermedio de mayor significación. Este rol ha sido desempeñado sostenidamente sólo por las gobernaciones de las provincias de Chañaral y Huasco, y no así por Copiapó. Debido a que la provincia de Copiapó alberga la capital regional, muchas veces las funciones de la gobernación son sobrepasadas por el Gore. Esta observación 
es ratificada en el nivel provincial, donde se subraya tanto la necesidad de una mayor definición de los ámbitos de competencia de la gobernación y la intendencia, como también la falta de personal calificado para asumir las funciones necesarias. Esto se agrava puesto que el Instructivo Presidencial no 155 entrega atribuciones, pero no recursos.

En el nivel comunal político y técnico de la comuna de Caldera, existe coincidencia en que el municipio tiene escasa o nula relación con la provincia de Copiapó. Esto obedecería al centralismo regional y al hecho de que la gobernación se encuentra en el mismo lugar que la intendencia. Al parecer, en el nivel técnico de la comuna se sabe que debiera haber una articulación con la provincia, lo que se implementaría durante este año 2005. Sin embargo, esto se entiende como la agregación de un nivel formal más para llegar a la intendencia, y no como una coordinación entre los actores de la comuna, ni menos como una articulación territorial entre las comunas que conforman la provincia

Articulación horizontal. El estudio encontró que, en general, en los distintos niveles se otorga importancia a la articulación de los actores de un mismo territorio. Se han desarrollado algunas formas de articulación, pero al parecer no se han instalado como prácticas permanentes.

En el nivel regional político se tiende a enfatizar la necesidad de articulación entre el Core y el intendente, si bien reconocen que la ley otorga al Core mínimas atribuciones. La articulación intendente-Core respondería más bien a un mecanismo para facilitar el proceso, que para asegurar los resultados.

En el nivel regional técnico se percibe también la necesidad de articulación entre el intendente y el Core, pero además se extiende la articulación hacia los sectores, los servicios públicos, el sector privado y, especialmente, hacia los alcaldes.

En el nivel comunal no se reconoce la necesidad de articulación o coordinación entre las comunas de la provincia. A juicio de algunos actores políticos, la diversidad existente entre las comunas que conforman la provincia hace imposible su articulación. Esto significa que la articulación de las comunas debe hacerse sobre ejes territoriales que le otorguen sentido de pertenencia a las distintas entidades que lo conforman, lo que puede no ajustarse a las divisiones político-administrativas.

Por último, no se le otorga una importancia especial a la articulación entre el alcalde y el Concejo Comunal, como tampoco se menciona su práctica.

En síntesis, se otorga distinta importancia a la articulación de los actores en el mismo territorio. Una importancia mayor se otorga en la región, mediante la articulación intendente-Core. La articulación se ve como necesaria no 
sólo en términos políticos, sino también técnicos. En el nivel de las comunas, por el contrario, no se otorga importancia a la articulación alcalde-Concejo Municipal. Se piensa que la articulación con las otras comunas de la provincia es importante, pero difícil de implementar debido a la diversidad de orientaciones económico-productivas que tienen las distintas comunas. Esto significa que los intentos por articular las comunas debieran orientarse a buscar puntos de encuentro de las comunas, que le otorguen sentido a un trabajo conjunto, independientemente de la división político-administrativa vigente.

Articulación intersectorial. El estudio encontró que se otorga importancia a la articulación intersectorial y se reconoce que se ha dado en los gabinetes ampliados. Si bien evaluadas como positivas, estas experiencias deben enfrentar resistencias que se basan en la cultura institucional de los sectores. Tales resistencias tienden a persistir a pesar de la buena voluntad que pueden tener algunas autoridades o funcionarios, lo que se ve reforzado por la antigüedad que tienen algunos de ellos. Se observa también la carencia de competencias técnicas para abordar e implementar exitosamente acciones intersectoriales institucionalizadas.

En el nivel regional político se subraya la importancia de la articulación entre los sectores. Sin embargo, se reconoce la existencia de descoordinaciones, lo que se relaciona tanto con falencias de tipo técnico, como también con las particularidades de cada sector. Se enfatizó la falta de coordinación de los servicios que dependen de una misma Seremía y también la falta de información que al respecto tienen, en algunas ocasiones, los propios Seremis:

el éxito es coordinación y seguimiento, coordinación entre unidades, por decirte algo, eh, de una Seremi dependen dos, tres, dos, tres servicios, digamos, y no están perfectamente coordinados, o no existen las suficientes confianzas como pa', ha tocado que un Seremi no sabe el tema que sí está pasando en un servicio que depende de él.

Región de Atacama — político

Además de la falta de coordinación e información de las Seremías, se observa también la ausencia de una visión intersectorial en los propios actores regionales encargados de conducir políticamente el proceso, como también una escasa formación y competencias técnicas para ello.

En el nivel regional técnico, se observa coincidencia respecto de que existe escasa coordinación intersectorial en la región. Las experiencias han radicado en los gabinetes ampliados, práctica que ha sido reforzada por el nuevo intendente: 
estamos usando los gabinetes ampliados, los gabinetes, las reuniones de las metas con los distintos sectores, con los técnicos incluso, tratando de atraer quizás a los técnicos que asesoran a los que toman las decisiones políticas en cada servicio público ellos también puedan llevar el mensaje que es "vinculémonos con otros servicios" para lograr quizás focalizar la inversión correctamente.

Región de Atacama — técnico

Aunque valorados positivamente, los intentos por estimular la intersectorialidad han enfrentado algunas dificultades relacionadas principalmente con la cultura institucional de cada sector, lo que se ve reforzado por la antigüedad de algunos funcionarios que tienden a reproducir dichas prácticas.

La participación y disposición de los sectores no es homogénea, lo que muchas veces depende del grado de interés e involucramiento de las autoridades de cada sector.

Por su parte, en el nivel comunal no se realizaron observaciones sobre la intersectorialidad en la región, lo que revela que no es un tema considerado como relevante para su gestión.

En síntesis, a diferencia de lo observado en el nivel comunal, en el nivel regional se le otorga importancia a la articulación intersectorial y se señala que los gabinetes ampliados son experiencias de este tipo. Aunque estas experiencias son vistas como positivas, aún son incipientes y han debido enfrentar resistencias fundadas en la cultura institucional de los sectores, que tienden a persistir a pesar de la voluntad de algunas autoridades o funcionarios. Se observa también la falta de competencias técnicas para abordar e institucionalizar prácticas intersectoriales, lo que sugiere la necesidad de capacitar a los funcionarios de los sectores en la modalidad de trabajo intersectorial.

Articulación sectorial-territorial. El estudio encontró que, concordando con lo observado en relación con la articulación intersectorial, en el nivel regional político y técnico se considera que la articulación de los sectores con el territorio es importante para el éxito del sistema de gestión regional. Existe la voluntad de incentivar e institucionalizar la perspectiva territorial, lo que, entre otras cosas, permitiría tanto instalar una visión regional, como también equilibrar los recursos que los sectores destinan a los distintos territorios.

El Gore ha operacionalizado esta perspectiva mediante intentos concretos que permitan focalizar la inversión de los sectores coordinadamente en los territorios.

Los intentos por institucionalizar la articulación sectores-territorio han enfrentado algunas dificultades basadas en los estilos de gestión de los sectores. En particular, porque éstos pueden focalizar sus recursos de acuerdo con sus propios criterios, sin considerar el territorio. 
La articulación sector-territorio se dificulta también porque gran parte de los recursos sectoriales son definidos a nivel central, lo que deja poco margen de maniobra para acercar los sectores a los territorios.

Sin duda, los esfuerzos orientados a institucionalizar la articulación sectores-territorio requerirán también de una mayor coordinación intersectorial y no sólo de los sectores con los territorios, en forma independiente. Esto obedece a que, como es esperable, cada sector prioriza el área de intervención que le corresponde. Un actor regional político, vinculado a un determinado sector, expresa claramente la posición de los sectores:

Las reglas regionales son, en primer lugar, hacer proyectos integrales, no proyectos de parches. ¿Qué significa proyectos integrales? proyectos que van asociados a un proyecto (sector X); si no hay proyecto (sector X), no hay inversión. O sea, eso está absolutamente claro, y le hemos hecho claridad en (entidad vinculada al sector X), cuando hay proyecto (sector X) de ahí comenzamos el proceso de postulación a una inversión, si no, no.

Región de Atacama - político

Las dificultades de articulación sector-territorio no representan un impedimento para que los sectores adquieran un papel protagónico. De hecho, algunos actores señalan que los sectores tienen roles activos cuando ellos son los involucrados directamente con un proyecto. En estos casos el rol de instalador o liderazgo del proyecto es central.

Por su parte, en el nivel comunal no se realizaron observaciones sobre la articulación sectores-territorio. Esto sugiere no sólo que se le otorga escasa importancia a este tema, sino que también no se ha integrado a los sectores como fuentes de obtención de recursos para la comuna.

En síntesis, la articulación sectores-territorio es vista como importante en el nivel regional político y técnico. Existen algunas iniciativas del Gore destinadas a fomentar esta articulación y transformarla en una práctica institucionalizada. De tener éxito, estas iniciativas permitirían tanto instalar una visión regional en los sectores, como también equilibrar los recursos que éstos destinan a los distintos territorios. Los intentos por institucionalizar la articulación sectores-territorio enfrentan obstáculos derivados de los estilos de gestión de los sectores, particularmente porque éstos pueden focalizar sus recursos de acuerdo con sus propios criterios, sin considerar los territorios.

No cabe duda que los esfuerzos por institucionalizar la articulación sectoresterritorio requerirán también de una mayor articulación intersectorial, que tienda a compatibilizar las prioridades de cada sector con las prioridades del territorio. Esto requiere de capacitación a los tomadores de decisiones, como también a los funcionarios técnicos que debieran poner en práctica el proceso. 


\title{
Capacidad política
}

Generación y articulación de redes. El estudio encontró que, en general, se otorga escasa importancia a la generación y articulación de redes como herramienta del sistema de gestión regional. Incluso, la mayoría de los actores no tocó directamente el tema. Existen algunas experiencias esporádicas en el nivel regional y su impacto aún no ha sido evaluado. Cabe destacar, sin embargo, que ninguno de los actores entrevistados utilizó el término "redes"2 para referirse a estas experiencias, lo que indica una baja asimilación y manejo de las redes como instrumento de gestión.

Aunque no se conceptualizan como redes, en el nivel regional político y técnico se mencionaron algunas experiencias que pueden ser identificadas como tales. Refiriéndose a la modalidad que asumió el proceso de planificación de la inversión en un sector, un actor regional político refiere a la búsqueda de consensos con el mundo privado empresarial:

Nosotros nos demoramos durante el año 2003 y gran parte del 2004 en tener finiquitado toda esta estructura que además fue consensuada con el sector privado de manera de poder llegar a las iniciativas, plasmarlas, generarlas y hoy día priorizarlas para poder trabajar con ellas en lo que es la gestión actualmente del actual intendente.

Región de Atacama — político

La inclusión del mundo privado es también señalada por un actor regional técnico, enfatizando que el sector público no puede subvencionar a la empresa privada:

\begin{abstract}
la empresa privada como le decía se ha involucrado derechamente (...) son las dos empresas que se han vinculado de una u otra manera a entender que la inversión que nosotros hacemos como gobierno regional, que al final va a quedar para ellos, ellos tienen que colaborarnos con los diseños, con los trazados, cosa que antes nos se hacía, nosotros derechamente estamos pidiendo que ellos ejecuten cosas y no estamos pidiendo ni un peso más, ellos se encargan de eso porque al final nosotros no podemos hacerles algo que va a quedar para ellos, ellos tienen que hacerlo.
\end{abstract}

Región de Atacama — técnico

Aunque escasas, las experiencias de trabajo en redes han incluido no sólo el mundo privado empresarial, sino también a las organizaciones vinculadas a éste.

\footnotetext{
${ }^{2}$ No se preguntó directamente por la existencia de redes.
} 
La generación de redes entre actores políticos clave de los distintos territorios es vista también como importante, especialmente la inclusión de los consejeros regionales. En este caso, las redes responderían a acuerdos políticos que viabilizarían las decisiones técnicas.

Por contraste a lo manifestado en el nivel regional, en el nivel comunal se le otorga poca importancia a la generación de redes, ya sea que éstas incluyan actores comunales, otros municipios, sector privado u organizaciones sociales. Por ejemplo, sólo un actor comunal político reconoció la falta de redes, manifestada en la escasa articulación con el mundo privado:

Desde mi perspectiva yo lo veo que no es mucha la participación del sector privado en este sentido, desde mi percepción, no podría decirle si sí o si no, pero mirándolo como un ciudadano común y corriente, que es como yo lo vi el año pasado, y eso me extrañaba porque aquí con las empresas que hay, que no son muchas pero podría haber otro, un aporte desde mi punto de vista, más importante hacia la comuna y no lo veo así.

Comuna de Caldera — político

En síntesis, se otorga escasa o nula importancia a la generación y articulación de redes como herramienta de gestión. Aunque no las conceptualizan como redes, se mencionan algunas experiencias que pueden ser identificadas como conducentes a tales. El impacto de estas experiencias no ha sido evaluado. Los actores tampoco entregaron información que permita tener una aproximación al respecto. El análisis sugiere la necesidad de reforzar la noción de creación de redes como instrumento de gestión territorial, tanto en los actores políticos como técnicos en todos los niveles, especialmente en el nivel comunal.

Influencia en las decisiones. El estudio encontró que se reconoce que las decisiones están radicadas en el nivel regional, particularmente en el Intendente y, en mucho menor medida, en el Core. La figura del gobernador es visualizada como no influyente. Se percibe la necesidad de ejercer acciones de influencia en los actores que toman las decisiones finales, es decir, intendente y Core. Se observa la ausencia de organizaciones sociales en estas acciones, ya sea en forma espontánea o motivada por la autoridad local.

En el nivel regional político se señala que las decisiones radican primero en la comuna y luego en el Gore. Por contraste, los gobernadores tienen una escasa o nula influencia en el proceso y sus resultados. Su acción, cuando existe, se reduce meramente a entregar opiniones.

La escasa influencia del gobernador es también aplicada a los consejeros regionales. El área de influencia del Core es más bien una formalidad que una realidad: 
en la comisión de inversiones, la verdad es que analizamos la cartera de proyectos que nos presentan ya sea por fondos FNDR, por PMU, Iral, Isar, y nosotros los eh, los analizamos vemos eh, el impacto económico o social que pueda digamos tener en la Región y tratamos eh, priorizarlo pero es entre comillas, porque la verdad es que yo considero que los proyectos ya vienen prácticamente eh, listos, o sea priorizados, pasan por el filtro de la Serplac, entonces a nosotros nos llega prácticamente como para claro, discutirlo, eh, pero no tenemos a pesar de que nuestras atribuciones son aceptar, rechazar o modificar.

Región de Atacama - político

La escasa influencia del Core es reconocida también en el nivel regional técnico. Desde algunas perspectivas, ni el gobierno regional ni los sectores le han otorgado al Core la importancia que merece.

los consejeros son como parlamentarios regionales entonces ése es una tema que yo creo que el gobierno regional tiene que asumir, que los consejeros, independiente de la experticia profesional que tengan, o la calidad humana que tengan, son personas que pueden definir, cortar o dirigir una política regional de desarrollo, y si están todos para un lado, se suena todo lo que uno quiere hacer, porque ellos focalizan. Ellos al final aprueban o rechazan y pueden decir "no queremos unos convenios de programación para allá, lo quiero para este lado", entonces eso es algo que creo que hay que considerar, reiterar la importancia de los consejeros a todo el gobierno regional, estoy hablando de servicios públicos también.

Región de Atacama — técnico

Si bien el Core aparece como no importante en el nivel de la región, adquiere cierta importancia en el nivel provincial. De hecho, un actor provincial político señaló que realizaba "lobby" con los consejeros, una vez que el Intendente había presentado la cartera.

Coincidiendo con el nivel regional, en el nivel comunal se señala que la figura del gobernador tiene escasa influencia en las decisiones. Incluso, un actor político comunal manifestó que esto tiene raíces históricas y que no cree que cambiará en el futuro cercano:

Yo creo que históricamente no ha habido ninguna coordinación provincial. Yo creo que no. Yo veo muy difícil la figura del gobernador en esta materia. Yo no, o sea, coincido plenamente en que debiera haber un nuevo rol más ejecutivo, más proactivo del gobernador, de la figura, del cargo del gobernador en términos de potenciar, en este caso, por último las diferencias, para generar un plan de desarrollo provincial. Pero como te 
digo, no lo he visto antes, no lo veo ahora y no sé sí será parte de lo que se viene.

$$
\text { Comuna de Caldera — político }
$$

En síntesis, se reconoce que las decisiones están radicadas en el nivel regional, particularmente en el Intendente. Un papel marginal se le otorga al Core, cuestión que a juicio de algunos debiera ser modificado por el Gore. La figura del gobernador es percibida como no influyente. Se menciona la realización de acciones de influencia o "lobby" sobre los tomadores de decisiones, en particular, de la gobernación provincial sobre los Cores.

Liderazgo. El estudio encontró que, en general, se reconoce la preeminencia de los liderazgos políticos por sobre los técnicos, lo que se evalúa en términos positivos. Se enfatiza el rol de liderazgo que deben desempeñar las autoridades unipersonales del nivel comunal y regional, mientras que se tiende a desestimar el rol de la autoridad provincial. Se reconoce y valora positivamente un fuerte liderazgo del Intendente, quien se relaciona directamente con los alcaldes y concejales de las distintas comunas de la región.

En el nivel regional político se reconoce un importante liderazgo del nuevo intendente, cuestión que no observan en los gobernadores y alcaldes.

En el nivel regional técnico se reconoce que el liderazgo del intendente ha permitido definir la modalidad de trabajo, en especial mediante la búsqueda de consensos con los actores políticos de la región. Como explica un actor regional técnico:

han pedido desde las mismas provincias que se sigan haciendo las reuniones donde el Intendente acude con todos los Seremis involucrados en temas relevantes y por lo tanto les permite ahí dar las soluciones en forma muy ejecutiva y eso es un trabajo muy bueno, han tenido una muy buena disposición todos los servicios públicos involucrados, los consejeros lo entienden e incluso ahora algunos consejeros le han planteado al Intendente que ahora sentían que ellos importaban y que valían, porque antes se les llevaban las cosas y ellos lo tenían que aprobar o rechazar, incluso no se les permitía rechazar, tenían que aprobar no más.

Región de Atacama — técnico

El liderazgo del intendente es visualizado también en el nivel comunal político, lo que se visualiza como un respaldo a la comuna. No obstante la importancia atribuida a la figura del intendente, se percibe la fragilidad de que los procesos descansen en las personas y no se instale una forma de procedimiento o, en otras palabras, que se institucionalice el sistema. Además 
de la figura del intendente como clave en el éxito del proceso, en el nivel comunal técnico se destaca también el rol de la alcaldesa, enfatizando que gran parte de los resultados finales obedecen a la gestión de las autoridades más que al trabajo técnico.

En síntesis, se otorga una alta importancia a los liderazgos políticos, dejando entrever que el éxito del sistema depende en gran medida de la capacidad de conducción de las autoridades unipersonales del nivel comunal y regional, mientras que se tiende a desestimar el rol de la autoridad provincial. Algunos actores perciben que la alta dependencia del liderazgo de las personas es riesgosa, porque el sistema de gestión puede durar lo que ciertas personas duren en sus cargos. Sin embargo, la mayoría confía en los liderazgos y no cuestiona la falta de institucionalización de los estilos de gestión que implementan tales liderazgos. Se reconoce y valora positivamente el fuerte liderazgo del actual intendente, quien se relaciona directamente con los alcaldes y concejales de las distintas comunas de la región.

\section{Confianza}

El estudio encontró que, en general, se manifiesta que existe confianza entre las distintas entidades que participan en el sistema de gestión de la región, especialmente en el ámbito de las decisiones políticas. Se señala que la confianza depende de la capacidad de responder oportunamente a las demandas de la comunidad. Cabe destacar que casi todos los actores se refirieron a problemas con el cumplimiento de los plazos, lo que incidía negativamente en la confianza, cuestión que estaba siendo superada en el último tiempo. Se señaló también que la transparencia de las acciones y la circulación de la información son elementos que favorecen la confianza.

En el nivel regional político se percibe que existe mayor confianza entre los niveles políticos que los niveles técnicos. En estos últimos incidiría una falta de claridad respecto de cómo se realizan los procesos, tanto en la selección de los proyectos como en relación con el monitoreo y evaluación:

yo creo que hay confianza entre las autoridades en los gobiernos comunales, con los provinciales, los regionales hay confianza en lo que están presentando. Y la desconfianza más bien es en los departamentos técnicos que hacen las propuestas (...)

Región de Atacama — político

Se confía en que un mayor esclarecimiento de los procedimientos técnicos debiera tender a aumentar los niveles de confianza. Sin embargo, también 
se señala que es posible continuar con ciertos proyectos a pesar de tener que cumplir con ciertas "formalidades" cuyo cumplimiento implicaría su atraso, lo que es una muestra de confianza.

Por su parte, en el nivel regional técnico se señala que se han profundizado las confianzas políticas, lo que ha hecho que los distintos actores tengan mayor certeza respecto de los fundamentos de las decisiones que están detrás de la aceptación o rechazo de un proyecto. El estilo de liderazgo del intendente ha fortalecido las confianzas entre los actores políticos y técnicos que implementan el sistema de gestión.

Un ejemplo se da en el caso del gobernador de Huasco, cuyo estilo de liderazgo ha permitido que los actores tengan una mayor comprensión de los procesos, aumentando la participación y la confianza entre los distintos actores y en el sistema:

El gobernador de Huasco yo creo que es un gran articulador de nuestro trabajo, es un gran colaborador de nuestro trabajo e incluso en algunos temas va delante de nosotros, don Armando Flores yo lo conocía de antes pero nos ha apoyado un montón, él ha logrado establecer un liderazgo entre los municipios y entre los técnicos, y eso generalmente no pasa (...) él pide actas, llega a acuerdos y cierra temas y dice "coloquemos como acuerdo tal cosa", todos de acuerdo, entonces él tiene un muy buen manejo de equipos y de grupos, eso facilita mucho el trabajo en Vallenar, por lo mismo uno le dice mucho al alcalde que le vamos a financiar 1 solo proyecto de los 86 que tenía en mente, él lo entiende, porque entiende que hay un trabajo técnico detrás de por qué le vamos a financiar 1 y no los 86 .

Región de Atacama — político

La transparencia y acceso a la información son otros elementos señalados. Sin embargo, se pone en duda la absoluta disponibilidad y transparencia de la información:

al menos yo siento que hay cierto nivel de confianza entre algunos de los actores que participan en el proceso. Hay ciertos niveles de transparencia también porque toda esta información se difunde, ellos siempre están enterados. Todo el tema de inversión está en internet y entonces cualquiera puede acceder a mirar, a ver qué proyectos están seleccionados, qué errate tienen. Por lo tanto, hay absoluta transparencia en eso. Eso sí hay que estar un poco involucrado y saber dónde buscar y cómo buscar, eso sí, pero la información está disponible. Y yo creo que el proceso de cómo se selecciona se ha trasparentado bastante, porque se les informa y todo el mundo sabe quién lo hace y cómo lo hace.

Región de Atacama — técnico 
En el nivel provincial, por su parte, también se señala que existen confianzas, aunque éstas entran en conflicto cuando cambian los interlocutores. Se señala que los funcionarios de Secplac de las comunas cambian con frecuencia, aunque en general se aprecia una buena disposición.

En el nivel comunal político se manifiesta que existe una menor confianza que la planteada en el nivel regional. Se enfatiza una gran influencia de factores políticos en el proceso, los cual debiera cambiar con la nueva administración regional y con una mayor diversidad política del Core:

Al menos, hemos coincidido. Se dijo en un momento y estuvimos todos de acuerdo que el norte de la comuna debiera ser el turismo y estuvimos todos de acuerdo. Se dijo qué proyectos queríamos, cuáles otros podíamos de alguna forma dejar parcelados y, en ese sentido, lo mismo que hemos dicho nosotros para el interior, lo hemos dicho para afuera también. Entonces, no sé si eso sea confianza, yo creo que es más un tema de honestidad.

Comuna de Caldera — político

La influencia de los factores políticos también es visualizada en el nivel comunal técnico:

las discusiones y todas las instituciones están, están destinadas a, y están destinadas a lo mismo, o sea, la preocupación que, que, de alguna u otra forma manifiesta el municipio, también la, la asumen los, el gobierno regional, las (...) con el Intendente y la elite (...)

Comuna de Caldera - técnico

En síntesis, se manifiesta que existe confianza entre las distintas entidades que participan en el sistema de gestión de la región. Se enfatiza la existencia de confianzas políticas más que técnicas, si bien se afirma que las confianzas se han profundizado producto de la nueva gestión del Gore, que ha tendido a profundizar y clarificar los procedimientos técnicos, como también a transparentar la información y las acciones, y a establecer estilos de gestión orientados a una mejora en el clima organizacional. En el nivel comunal se manifiesta la influencia de factores políticos como aspectos que inciden negativamente en la confianza. Además, se afirma que existe menor confianza que la percibida por los actores regionales.

\section{Participación}

Participación institucional. El estudio encontró que se valora positivamente la participación institucional, la que se entiende como dependiente del liderazgo 
de cada nivel. Se enfatiza la participación del Gore y el municipio, lo que ha sido principalmente estimulado por la nueva autoridad regional. Se manifiesta que la participación del Core es limitada debido a las restricciones que le otorga la ley. Además, se visualiza a la gobernación con una escasa participación en el proceso. En relación con la participación sociopolítica, se reconoce que es escasa o inexistente, pero no se visualiza como un elemento importante del sistema de gestión. Algunos actores piensan que pueden abrir canales de participación por medio de los instrumentos de gestión.

En el nivel regional político se identifica al gobierno regional (en especial coordinadores territoriales, Sagore y Serplac) y a los municipios como los principales actores que participan en el sistema de gestión. Por contraste, se le asigna escasa o nula o participación a las gobernaciones:

yo creo que el rol que han jugado ellos (los coordinadores territoriales) es apoyar el levantamiento de proyectos básicamente, también entiendo que han participado en la coordinación de algunos, básicamente eso, digamos, apoyan la formulación y lo otro, mantener los nexos hacia las divisiones del gobierno regional, ahora, como digo, los gobernadores no percibo claramente que hayan tenido una participación mayor en esto, salvo desde el punto de vista de la formalidad, que en algún momento a ellos les llega la posibilidad de tomar una especie de priorización o asignar una especie de priorización a los proyectos, obviamente están los, la Secretaría Regional de Planificación, y ahí la figura principal son los sectorialistas, y por parte del gobierno regional, percibo una gran participación del jefe de División de Análisis y Control de Gestión, y algunos jefes de departamento que tienen mayor relación con lo que es la cartera de proyectos, son un poco los actores básicos.

Región de Atacama - político

La participación de los Cores se ve en general limitada y dependiendo más de la iniciativa individual de cada Core.

En el nivel regional técnico existe consenso respecto de que el actor institucional con mayor participación en el sistema de gestión es el Gore, teniendo el Core una participación limitada a las atribuciones que le otorga la ley. A diferencia con lo observado en el nivel regional político, se le otorga mayor énfasis a la participación de los municipios:

(las autoridades locales) son el motor de todo este cuento, porque ellos son los que formulan las iniciativas, la mayoría de las iniciativas, porque también hay iniciativas que presentan los sectores. Por lo tanto, es súper importante el rol de ellos y yo siento que sí es bastante activa, hay municipios que son un 
poco más quedaditos que otros, pero en general yo he visto bastante participación, no sólo de la Secplac, de sus municipios, sino también de sus alcaldes en este tema de estar en las reuniones, de participar, de estar preocupado de que efectivamente se prioricen las iniciativas que a ellos les interesan. Por lo tanto, son ellos en el fondo quienes deciden qué iniciativas les interesan y por lo tanto es fundamental.

Región de Atacama — técnico

El nivel provincial coincide en la mayor participación del Gore, especialmente de la unidad de control, que lleva el trabajo técnico. Se reconoce también el rol coordinador de la gobernación provincial, y a nivel del municipio se identifica el rol político del alcalde y el rol técnico del Secplac. Se señala también la participación de algunos servicios públicos, en algunos proyectos determinados.

En el nivel comunal político existe coincidencia, con los otros niveles, respecto de que la mayor participación radica en los actores del Gore y que la gobernación tiene escasa injerencia. La participación del Gore ha aumentado en el último tiempo, lo que es visto en términos positivos:

A ver, para mí a nivel de Intendencia yo creo que se ha hecho un buen trabajo en el sentido de empezar a gestionar esta gran forma de trabajar los proyectos que se armen, y con una decisión efectiva digamos, no retórica. Ahora el gobernador provincial como te digo tengo entendido que hizo una reunión, pero no he tenido mayor información del trabajo que él haya realizado coordinar o para llevar a cabo esta nueva forma.

Comuna de Caldera - político

Existe coincidencia, además, respecto de que la participación de los Cores es limitada:

yo creo que, por un lado, acá se inició conversaciones con los consejeros regionales de acá y yo creo que es bueno involucrarlos. No siempre se previene a los consejeros regionales y al final los consejeros regionales terminan sabiendo en la misma reunión de qué se trata el proyecto que se está presentando. Por otro lado, no sé, es como lo único que yo veo que podría haber más participación de los consejeros.

Comuna de Caldera — político

En el nivel comunal técnico, por su parte, también se otorga al Gore un rol predominante. Sin embargo, a diferencia de los niveles regional y comunal político, se visualiza el proceso como estandarizado y no se identifica otros actores, como el gobernador o el Core. 
Además, se enfatiza que el Gore debiera tener sobretodo un rol de soporte técnico del municipio. Un mayor apoyo del Gore se traduciría en una mayor cartera de proyectos que el municipio podría presentar, puesto que los profesionales del municipio no pueden abarcar la diversidad de temas que el trabajo exige.

En síntesis, existe coincidencia en todos lo niveles respecto de que la participación institucional se expresa a nivel del Gore y los municipios, en sus dimensiones políticas y técnicas. Existe coincidencia también en que la participación de los Cores es limitada, pero no existe una visión sobre cómo puede ampliarse tal participación, de manera tal que constituya más que una mera formalidad. En el nivel comunal se enfatiza la necesidad de tener una mayor participación del Gore en cuanto apoyo técnico a la unidad técnica del municipio.

Participación de las organizaciones sociales y políticas. El estudio encontró que en el nivel regional político se afirma que existe una escasa participación de las organizaciones sociales y políticas en todos los niveles del sistema de gestión. Sin embargo, se piensa que este tipo de participación debiera darse principalmente a nivel de los municipios, lo que en cierta forma desconecta a los actores regionales de la responsabilidad de estimular la participación, o abrir canales para ella:

Por lo menos en mi experiencia (...) en el proceso de generación de ideas al menos, que pudiera ser una parte donde se asumiría que mucho más naturalmente podrían participar, no he tenido la experiencia de conocer ni participar en ningún tipo de evento de ninguna naturaleza que tenga que ver con eso, en donde las organizaciones sociales puedan expresar necesidades respecto a lo que sucede, sus visiones acerca de lo que sucede en sus comunas (...)

Región de Atacama - político

De alguna manera, se atribuye a las organizaciones sociales la responsabilidad de la escasa participación, afirmando que sólo se movilizan por situaciones que les afectan directamente:

Las organizaciones sociales, yo diría tiene algún grado de interés en esto cuando les toca a ellos, si les toca a ellos en el punto, entonces ahí se preocupan, pero nosotros cuando se van a hacer algunas actividades con juntas de vecinos, entonces ahí ellos se inquietan y vienen, o la, u otras organizaciones.

Región de Atacama - político

Pese a atribuirle cierta responsabilidad a las organizaciones sociales en su escasa participación, se visualiza que es posible estimular la participación a 
través de mecanismos institucionales situados en el nivel de los municipios. Se reconoce que abrir canales de participación sociopolítica es una deuda pendiente en la región, planteando que un mecanismo para estimularla podría ser que las organizaciones sociales dieran un "RS" a los proyectos.

El nivel regional técnico coincide con el político en que la participación de las organizaciones sociales y políticas es prácticamente inexistente. Sin embargo, se reconoce especialmente la falta de participación en las instancias regionales.

Se observa cierto reconocimiento de la responsabilidad que le cabe al Gore en la escasa participación de las organizaciones sociales, al menos en el sentido de buscar canales para impulsarla. Se señala que la idea de la actual administración es potenciar la participación. Se observa, sin embargo, cierta reticencia a abrir canales de participación, pues implica el riesgo de que se traduzca sólo en peticiones por parte de las organizaciones sociales:

creo que nos falta vincularnos más con las estructuras sociales, con las organizaciones sociales, eso yo no desconozco que yo no lo he hecho ... no hemos hecho un intento en eso, de conocer las estructuras de cuántas son agrupaciones de jóvenes, de adulto mayor, sé que están organizados pero no tenemos mucha vinculación con ellos, básicamente porque queremos ir ordenando a todo el mundo para cuando lleguemos a ellos, los requerimientos que ellos tengan para priorizar la inversión, porque todo genera una pedida $(. .$.

Región de Atacama — técnico

Por su parte, en el nivel provincial se señala la inexistencia de participación de las organizaciones y se menciona que existe un tipo de participación indirecta: las organizaciones y la comunidad están representadas por los concejales.

En el nivel comunal político y técnico se reconoce también la falta de participación en el sistema de gestión. Aunque algunos actores manifiestan que hay cierta participación de organizaciones sociales para presentar determinados proyectos, todos los actores reconocen que, en general, no existe participación en el sistema.

En síntesis, existe consenso respecto de que la participación de las organizaciones sociales y políticas en el sistema de gestión es nula o inexistente. En el nivel regional político se tiende a pensar que este tipo de participación es más propia del nivel comunal que del regional. En el nivel regional técnico, por contraste, se le otorga un espacio a nivel de la región. En el nivel comunal se enfatiza la falta de participación en el proceso que desarrolla el municipio. 
Es importante mencionar que existen diferentes formas de ver la participación: involucramiento de las organizaciones sociales en proyectos determinados; participación en la priorización de los proyectos; participación en la aprobación de cada proyecto. Si bien estas instancias no son excluyentes y se debiera tender a la inclusión de todas ellas, el análisis revela que los actores coinciden en la falta de participación en el proceso, pero no coinciden en cuál es el rol que la ciudadanía u organizaciones sociales debieran tener en el proceso. Las estrategias para fomentar el sistema de gestión en esta región debieran, al menos, considerar instancias de discusión para que los actores puedan reflexionar respecto de las formas de participación posibles y las medidas deben tomar para alcanzarla.

\section{Componente institucional}

El componente institucional del sistema de gestión regional es la dimensión en la que se apoya la estructura decisional político-administrativa, por medio de la utilización de las normas y de los instrumentos de planificación y gestión, tales como Estrategia Regional de Desarrollo (ERD); Presupuesto Regional; Sistema Nacional de Inversiones (SNI), entre otros. Incluye el conocimiento y aplicación de normas e instrumentos, como también las particularidades de la implementación del sistema en una región específica, lo que incide en su institucionalización.

\section{Conocimiento y aplicación de normas e instrumentos}

Desde esta perspectiva, se observa la percepción de los actores en la utilización de las normas legales que sustentan el aparato político administrativo de gestión. Se analiza la percepción respecto de la aplicabilidad y utilidad de la legislación y la normativa vigente. La idea central es visualizar cómo los actores se refieren a la utilidad de la normativa vigente vinculada al logro de sus objetivos y funciones. Se trata también de entender cuál es el valor crítico que le dan a la normativa y si esta les permite ordenar y mejorar sus procesos de gestión regional. Para ello, se examina la utilización de la legislación y normativa vigente en sus aspectos tecno-administrativos, como también el manejo conceptual de los actores institucionales del sistema de gestión.

En cuanto a los instrumentos de gestión, se indaga sobre la percepción de uso de las herramientas de planificación y gestión regional y como de programación de inversiones establecidos por la normativa vigente en las distintas unidades territoriales a saber; la región, provincia o comuna. Por últi- 
mo, se analiza la capacidad de creación y utilización de otros instrumentos legales para el funcionamiento del sistema de gestión regional, en particular, si se han creado algún tipo de reglamento que sustente las herramientas que se han desarrollado en la misma región.

El estudio encontró que, en general, los actores no identifican instrumentos jurídicos específicos, si bien se observa que en general saben que existen tales instrumentos. En su mayoría no identifican el Instructivo Presidencial no 155 , con excepción de algunos actores que han tenido que utilizarlo directamente. Los actores tienden a entender el Pladeco y EDR como instrumentos normativos y no como instrumentos para la gestión, lo que dificulta que los incorporen como herramientas para la implementación del sistema de gestión. Del análisis se desprende que existen bajos niveles de discusión y preparación técnica sobre instrumentos y funcionamiento del sistema de gestión regional, lo que sugiere la necesidad de evaluar las necesidades de capacitación y profesionalización en todos los niveles del sistema de gestión regional.

En el nivel regional político los actores coinciden en que no existe una metodología precisa para establecer la priorización de los proyectos que efectúa el intendente. Sin embargo, tienden a mencionar que el marco global es la EDR.

Además de la EDR, otro instrumento identificado como parte del sistema de gestión es el marco lógico, herramienta que es definida como un instrumento novedoso, a pesar de que fue creado hace más de dos décadas. Según un actor regional político, la introducción de esta herramienta permitiría distinguir una nueva fase en el proceso que ha tenido lugar en la región:

Yo diría que claramente hay 2 principios, 2 momentos en términos de la
gestión regional que tienen que ver con la decisión de inversión. El primero
de ellos que se desarrolló el año 2002, que básicamente dada la estructura
que existía y los compromisos asumidos por el gobierno regional tenían que
ver básicamente con cristalizar los compromisos asumidos en la estrategia
de desarrollo regional, en relación a los convenios que se habían estructurado
entre ministerios y entre el gobierno regional y el nivel central para coordinar
las decisiones de inversión, eso fue durante el año 2002 . El año 2003 inici-
amos un proceso distinto que básicamente este proceso fue encabezado por
la actual ministra de Mideplan, (...), en el sentido de aplicar una metodología
distinta, (...), cual es la del marco lógico para poder definir la inversión a
partir del análisis de los problemas estructurales que enfrentaba la región
de Atacama. Región de Atacama — político

Se visualiza que se debe potenciar la visión de conjunto, compatibilizando los instrumentos que existen en los distintos niveles. Desde esta perspectiva, 
los instrumentos de planificación (Pladecos, EDR) son vistos más bien como instrumentos normativos que como instrumentos de gestión. Se piensa que los nudos críticos del sistema están en el nivel de los municipios, los que no han entendido que sus propuestas deben responder a los instrumentos de planificación local y la EDR.

En el mismo marco del desarrollo de una visión de conjunto en los distintos niveles territoriales, se subraya la necesidad de desarrollar una actitud cooperativa con vistas al desarrollo de la región, lo que implica ciertas redefiniciones de las funciones asignadas a funcionarios del Gore y a los sectorialistas. Respecto de éstos últimos, remitirse sólo a la evaluación y apoyo técnico, una vez que se ha decidido los proyectos de interés para el municipio, con base en su correspondencia con el Pladeco respectivo y la EDR:

yo no sé si será sano que los sectorialistas participen antes del proceso de formulación, en el fondo pasarían a ser casi voz y parte, por lo tanto, debe mostrar su propia vía, ahora, la división con respecto a los jefes de departamento del gobierno regional de ellos sí podría precisamente, a partir de lo que se supone que ellos tendrían, que es la visión de conjunto, tratar de orientar de mejor manera los procesos de formulación a nivel local, a nivel provincial, a nivel regional; en el caso de los sectorialistas, yo creo que el compromiso mayor está en que una vez definida esta concordancia o generada esta coherencia entre los distintos instrumentos de planificación, prioridades políticas, realidades que se van creando en, digamos, en un momento o en una realidad, digamos, de más corto plazo, ellos pudieran sentirse mucho más llamados, no sólo a evaluar técnicamente los proyectos, sino a generar condiciones para que las unidades técnicas puedan apostar a que, como siempre falta, o levantar aquellas observaciones que se le han formulado, yo a veces percibo que como, no sé, como aquel profesor de la universidad que dice que mientras más alumnos reprueba, mejor considerado es como académico, en este caso, al parecer un poco la lógica es que un sectorialista mientras más proyectos rechaza, y no reconozca la recomendación técnica, al parecer se creería mejor sectorialista.

Región de Atacama — político

Los actores regionales políticos coinciden no sólo en la necesidad de desarrollar una actitud cooperativa y una visión de conjunto, sino también en que los municipios cuentan con pocas capacidades técnicas para lograr este objetivo:

a nivel comunal, digamos, hay deficiencias o faltan profesionales que se aboquen y que estén acostumbrados a trabajar con metas.

Región de Atacama - político 
Se plantea que una vía para suplir la falta de competencias técnicas de los municipios puede ser profundizar la cooperación de la Serplac.

Por su parte, en el nivel regional técnico los actores coinciden con los actores regionales políticos en la falta de capacidades técnicas de los municipios:

(los municipios) ellos muchas veces solamente piden la inversión, pero ellos muchas veces no colocan nada en cuanto a que la gestión se haga en forma correcta, nosotros podemos transferir una inversión, un servicio público puede hacer una inversión, pero muchas veces los municipios no ejecutan correctamente la parte que les corresponde a ellos cuando hay una inversión que requiere de la ficha CAS y requiere del trabajo territorial que se les pide también para identificar a los beneficiarios, o sea ahí estamos pidiendo también una colaboración muy valiosa.

Región de Atacama — técnico

La falta de competencias técnicas aparece especialmente en los municipios pequeños. Algunos dudan, sin embargo, que esto pueda resolverse con capacitación, sugiriendo que es necesaria una dotación extra de personal.

En general, en el nivel regional no se realizan menciones particulares al Instructivo Presidencial no 155 . Un actor regional técnico describe el proceso de difusión de este instrumento, identificando algunos vacíos relacionados con que no establece la modalidad de implementación del FNDR, Iral e Isar, como también un desconocimiento general de este instrumento:

El año 2002 partimos con la aplicación del 155, por lo tanto trabajamos bastante en pañales en eso, digamos. Había salido recién, hace poco tiempo el 155 y los gobernadores estaban recién empapándose del tema, por lo tanto fue un año más bien de aprendizaje y de capacitación. En esa oportunidad nosotros tuvimos que ir a las provincias y explicarles bien en detalle en qué consistía el 155, cómo operaba. Hicimos el mismo ejercicio al interior de los gabinetes para que también conocieran que existía este oficio, porque la verdad es que nadie lo conocía. A excepción de los gobernadores, los demás no lo conocían, si bien entiendo que les había llegado también a los ministros, no había habido una suerte de bajada a nivel de los Seremi y de las direcciones regionales, por lo tanto, ese año fue como de darlo a conocer y ver cómo en la región se implementaba un procedimiento para aplicarlo, porque el cuento era que se decía que había que respetar ciertos porcentajes en ciertas fuentes de financiamiento - el FNDR o la inversión Iral, que era la otra que estaba, o la inversión Isar - pero no se decía cómo sino que cada región debía implementar el procedimiento.

Región de Atacama - técnico 
Por su parte, en el nivel comunal político los actores coinciden con los actores regionales en la necesidad de contar con una visión de la región.

Reconociendo la necesidad de contar con una visión regional, se subraya que la comuna de Caldera cuenta con un reciente Pladeco, afirmando fue elaborado con gran participación de la comunidad y que responde a los lineamientos de la EDR. Existe confianza en que el Pladeco se convertirá en un verdadero instrumento de gestión y no quedará sólo en una declaración de intenciones. En el nivel comunal técnico se coincide con esta visión, señalando además que la búsqueda de fondos por parte del municipio no debe restringirse al FNDR:

la municipalidad peca en el sentido de que siempre busca el mismo tema, el mismo fuente de financiamiento lo que es el FNDR, por lo tanto, la tarea es nosotros, si bien hay muchos proyectos que van a Fondo Nacional de Desarrollo Regional tenemos que trabajar por los cargos otros fuentes de financiamiento que permitan eh, lograr el, el objetivo de la ejecución tanto de obra e infraestructura como también de programas y estudios que también están dentro de la cartera de proyectos.

Comuna de Caldera - técnico

En síntesis, los actores conocen en general la existencia de instrumentos jurídicos del sistema de gestión. Sin embargo, en su mayoría no identifican el Instructivo Presidencial no ${ }^{\circ}$ 155. Se entiende el Pladeco y EDR como instrumentos normativos más que como instrumentos para la gestión, lo que dificulta que estos instrumentos sean incorporados como herramientas para la implementación del sistema de gestión. Sin embargo, la reciente formulación del Pladeco en la comuna de Caldera representa una oportunidad para incorporarlo, hecho que es reconocido por los actores comunales. El análisis revela que existen bajos niveles de discusión y preparación técnica sobre instrumentos y funcionamiento del sistema de gestión regional. Se sugiere realizar una evaluación de las necesidades de capacitación y profesionalización en todos los niveles del sistema de gestión regional.

\section{Particularidades del modelo}

El estudio encontró que algunos actores identifican ciertos elementos que serían distintivos de su sistema de gestión, respecto a otras regiones o comunas. Los elementos distintivos que se señalan están relacionados con la instalación de los 
gabinetes o el Plan Maestro de Inversiones. Otros actores señalan que no visualizan ningún elemento distintivo. Tiende a existir consenso respecto de que la nueva gestión del intendente imprimirá un sello distintivo en la región. Las coincidencias/divergencias de los distintos actores son sumamente relevantes, puesto que indican cómo están mirando el sistema, sus nociones sobre lo que pasa en otras regiones y comunas, ambos aspectos constituyentes de los niveles de formación respecto del funcionamiento del sistema de gestión en tanto modelo ideal diseñado por la Subdere y modelo real aplicado en las regiones.

En el nivel regional político los actores tienen dificultades para encontrar elementos distintivos. Uno de ellos hace hincapié en el Plan Maestro de Inversiones o Agenda Atacama, como instrumento que distingue lo que se ha hecho en esta región respecto de otras regiones:

la gran gracia del Plan Maestro de Inversiones es que de una manera metodológica hace carne de las grandes declaraciones que se hacen el la Estrategia de Desarrollo Regional, la Estrategia de Desarrollo Regional, por lo menos en esta región parecían grandes iniciativas de discurso, pero de ahí a poderlas plasmar en algo concreto, en iniciativas de inversión había una distancia que de alguna manera, o de una manera importante este plan maestro permitió de alguna manera avanzar.

Región de Atacama — político

Otro actor regional político señala la dificultad de encontrar elementos distintivos y plantea que uno de ellos puede ser rescatar los fines que las mismas comunas plantean, lo que por cierto está en la base del sistema de gestión:

si hubiera algo que yo quisiera marcar quizás como un elemento distintivo
de lo que hemos estado haciendo ahora, es precisamente eso, tratar de ir
induciendo digamos, todos los instrumentos de inversión hacia fines que
ellos mismos están planteando como comuna.

Región de Atacama — político

En el nivel regional técnico los actores también tienen dificultades para identificar elementos distintivos de su sistema de gestión. En general, afirman que lo que ocurre en esta Región es similar a lo que ocurre en las otras. Uno de ellos, sin embargo, destaca con entusiasmo la instalación de los gabinetes, o mesas de trabajo, según la denominación de la Subdere, como también la existencia de un Plan Plurianual de Inversiones:

Claro, salen los gabinetes también. De esos tres (Infraestructura, Fomento Productivo y Social) nosotros dijimos “ya po' bajemos", porque la estrategia 
son lineamientos, son orientaciones generales, así que "bajemos a llegar a definir proyectos, iniciativas de inversión para poder financiar". Se hizo todo un trabajo y entiendo que nosotros en esto somos pioneros, lo digo con orgullo porque no todas las regiones tienen un plan plurianual de inversiones asociado a su estrategia, sino que todos tienen proyectos de presupuestos anuales, nosotros tenemos este plan plurianual.

Región de Atacama — técnico

Al igual en el nivel regional, en el nivel comunal los actores tienen dificultades para identificar elementos distintivos del proceso en su comuna en relación con otras comunas de la misma región o el país y ninguno señaló elementos específicos.

En síntesis, aunque algunos actores identifican ciertos elementos que distinguen su sistema de gestión respecto de otras regiones o comunas, la mayoría tiene dificultades para identificar tales elementos. Los elementos identificados son más bien propios de la definición del sistema de gestión, que de su implementación en esta región. Existe cierta tendencia a manifestar que la nueva gestión del intendente imprimirá un sello distintivo en la región, lo que ratifica que hasta ahora no han visto elementos distintivos. El análisis revela dificultades en la institucionalización del sistema, pues los actores no logran identificarse con un sistema propio. También, indica que existen deficiencias en las competencias técnicas, pues entregan escasas referencias a lo que ocurre en otras regiones o comunas. Todo esto señala la necesidad de evaluar las competencias técnicas en los distintos niveles y realizar la capacitación que dicha evaluación indique.

\section{Conclusiones}

\section{Componente político del sistema de gestión regional}

Articulación y coordinación político-administrativa de los actores

\section{Articulación Vertical}

口 En los distintos niveles se observa coincidencia respecto de que existe algún tipo de integración espacial político-administrativa entre la Región, las provincias y las comunas, dejando fuera el rol de la nación. Sin embargo, se observan algunos matices entre estas visiones. 
口 En el nivel regional político, la articulación es percibida como un eje regióncomuna, donde los gobernadores tienen algún rol articulador, si bien su ámbito de acción está sujeto a las acciones del Gore y las decisiones del intendente. El eje región-comuna se entiende como conciliador de los intereses de la región con los de la comuna, teniendo a la región como territorio determinante. Esto puede verse dificultado por las atribuciones de los niveles intermedios, ya sea los gobernadores o los consejeros regionales. En otras palabras, la articulación provincia-comuna es vista como positiva en sus etapas iniciales, pero luego es vista como un obstáculo, cuando se mantiene la visión de la provincia por sobre la visión de la región.

口 En el nivel regional técnico se visualiza también el eje región-comuna, otorgándole a las gobernaciones provinciales un rol intermedio de mayor significación. Este rol ha sido desempeñado sostenidamente sólo por las gobernaciones de las provincias de Chañaral y Huasco, y no así por Copiapó. Debido a que la provincia de Copiapó alberga la capital regional, muchas veces las funciones de la gobernación son sobrepasadas por el Gore.

口 Lo anterior es ratificado en el nivel provincial, donde se subraya tanto la necesidad de una mayor definición de los ámbitos de competencia de la gobernación y la intendencia, como también la falta de personal calificado para asumir las funciones necesarias. Esto se agrava puesto que el Instructivo Presidencial no 155 entrega atribuciones, pero no recursos.

u En el nivel comunal político y técnico existe coincidencia en que el municipio tiene escasa o nula relación con la provincia. Esto obedecería al centralismo regional y al hecho de que la gobernación se encuentra en el mismo lugar que la intendencia. Al parecer, en el nivel técnico de la comuna se sabe que debiera haber una articulación con la provincia, lo que se implementaría durante este año 2005. Sin embargo, esto se entiende como la agregación de un nivel formal más para llegar a la intendencia, y no como una coordinación entre los actores de la comuna, ni menos como una articulación territorial entre las comunas que conforman la provincia.

a Los resultados descritos señalan que existe capacidad de articulación de la región en sus distintos niveles territoriales. Esto permitiría desarrollar un proceso de articulación vertical, pues existe una tendencia clara a implementar una relación de integración región-comuna. Se estimula una visión de integración regional más directa entre comuna-región, lo cual tiene fortalezas y debilidades.

u Las fortalezas se relacionan con poder mantener la integralidad de la región respecto del sistema de gestión regional. Por tanto, se viabiliza con mayor 
facilidad la integración de los distintos territorios locales, lo que puede generar un mayor equilibrio territorial. De hecho, esto conduciría a que las autoridades regionales tengan una mirada panóptica de la región, mientras las autoridades comunales observen cómo su comuna se integra con el resto de la región.

口 Las debilidades de esta perspectiva de integración son de tipo político y de gestión. Desde el punto de vista político, se puede producir el desgaste de las autoridades regionales al tener que estar presentes en cada una de las comunas, tanto en el inicio de los procesos de priorización como en su seguimiento. También, se puede presentar el favoritismo político por comunas que son del conglomerado de gobierno, por sobre aquellas que pertenecen a la oposición. Desde el punto de vista de gestión, se puede producir el fenómeno de duplicación de acciones, es decir, visitas permanentes de equipos de apoyo a las distintas comunas de la región, perjudicando la gestión de global de la región. Por último, el no utilizar a las gobernaciones como órganos coordinadores intermedios aumenta los costos de operación del sistema de gestión regional. Esto se produce porque desaparece la economía de escala que generan las instancias de coordinación de las comunas de una misma provincia.

口 La idea de articulación territorial comuna-región que se presenta en esta región es posible siempre y cuando se considere las fortalezas y debilidades señaladas. Para que este sistema de gestión funcione, en una primera etapa se debieran articular los territorios de gestión y, en su interior, las comunas que pertenecen a él. En una segunda etapa se debiera realizar la transición de los procesos de coordinación del territorio de gestión a las gobernaciones.

\section{ARTiCUlación HORIZONTAL}

- Se otorga distinta importancia a la articulación de los actores en el mismo territorio. Una importancia mayor se da en la región, mediante la articulación intendente-Core. La articulación se ve como necesaria no sólo en términos políticos, sino también técnicos.

a En el nivel de las comunas, por el contrario, no se otorga importancia a la articulación alcalde-Concejo Municipal. Se piensa que la articulación con las otras comunas de la provincia es importante, pero difícil de implementar debido a la diversidad de orientaciones económico-productivas que tienen las distintas comunas. 
a Los intentos por articular las comunas debieran orientarse a buscar puntos de encuentro de las comunas, que le otorguen sentido a un trabajo conjunto, independientemente de la división político-administrativa vigente.

\section{ARTICULACIÓN INTERSECTORIAL}

口 En el nivel regional se le otorga importancia a la articulación intersectorial y se señala que los gabinetes regionales ampliados son experiencias de este tipo. Aunque estas experiencias son vistas como positivas, aún son incipientes y han debido enfrentar resistencias fundadas en la cultura institucional de los sectores, que tienden a persistir a pesar de la voluntad de algunas autoridades o funcionarios.

口 En el nivel comunal no se realizaron observaciones sobre la intersectorialidad en la forma independiente, lo que sugiere que no es un tema considerado como relevante para su gestión.

口 El análisis revela una falta de competencias técnicas para abordar e institucionalizar prácticas intersectoriales, lo que sugiere la necesidad de capacitar a los funcionarios de los sectores en la modalidad de trabajo intersectorial.

\section{ARTiCULACIÓN SECTORIAL-TERRITORIAL}

ㄴ La articulación sectores-territorio es vista como importante en el nivel regional político y técnico. Existen algunas iniciativas del Gore destinadas a fomentar esta articulación y transformarla en una práctica institucionalizada. De tener éxito, estas iniciativas permitirían tanto instalar una visión regional en los sectores, como también equilibrar los recursos que éstos destinan a los distintos territorios.

ㄴ Los intentos por institucionalizar la articulación sectores-territorio enfrentan obstáculos derivados de los estilos de gestión de los sectores, particularmente porque éstos pueden focalizar sus recursos de acuerdo con sus propios criterios, sin considerar los territorios.

․ Los esfuerzos por institucionalizar la articulación sectores-territorio requerirán también de una mayor articulación intersectorial, que tienda a compatibilizar las prioridades de cada sector con las prioridades del territorio. Esto requiere de capacitación a los tomadores de decisiones, como también a los funcionarios técnicos que debieran poner en práctica el proceso. 
口 Tanto para la articulación horizontal como para la intersectorial y la sectorialterritorial, lo principal es que la región reconoce su potencialidad. Sin embargo, los actores también reconocen que existe un problema cultural que genera resistencias al proceso de articulación. Se propone intervenir en dos ámbitos. Primero, reforzar las acciones de coordinación interinstitucional por medio de los gabinetes regionales ampliados. Segundo, capacitar a los directivos regionales en una primera etapa y, en una segunda, a los profesionales de cada sector. La capacitación debiera permitir que directivos y profesionales conozcan las modalidades posibles de integración con otros servicios, como también comprendan e implementen la idea de gestión en red de los servicios públicos regionales. Se debe enfatizar en que gran parte de los servicios tienen beneficiarios comunes, o un territorio de intervención en común.

a El aspecto clave de la capacitación descrita es generar, en los directivos y profesionales, competencias y habilidades referidas a cómo se planifica, organiza, coordina y dirige los procesos de integración y articulación entre sectores especializados. Se trata, fundamentalmente, de una formación de carácter metodológico-práctico donde los elementos estructurales del proceso formación son la integración y articulación entre distintos sectores con los ejes territoriales integrados por las comunas, y coordinados por las gobernaciones o coordinaciones territoriales. Un elemento central del método de enseñanza aprendizaje es el análisis y discusión de casos que refieran experiencias de GTI, provenientes de otras regiones.

\section{Capacidad política}

\section{GENERACIÓN Y ARTICULACIÓN DE REDES}

口 Se otorga escasa o nula importancia a la generación y articulación de redes como herramienta de gestión.

口 Aunque no se conceptualizan como redes, se mencionan algunas experiencias que pueden ser identificadas como conducentes a tales. El impacto de estas experiencias no ha sido evaluado. Los actores tampoco entregaron información que permita tener una aproximación al respecto.

El análisis sugiere la necesidad de reforzar la noción de creación de redes como instrumento de gestión territorial, tanto en los actores políticos como técnicos en todos los niveles, especialmente en el nivel comunal. 
․ Se reconoce que las decisiones están radicadas en el nivel regional, particularmente en el intendente. Un papel marginal se le otorga al Core, cuestión que a juicio de algunos actores debiera ser modificado por el Gore.

․ La figura del gobernador es percibida como no influyente.

u Se menciona la realización de acciones de influencia o "lobby" sobre los tomadores de decisiones, en particular las que realiza la gobernación provincial sobre los Cores.

口 Este tema debe ser abordado por medio de las recomendaciones ya señaladas. Esto significa que, si se logra instalar una nueva forma de gestión regional, los procesos de lobby debieran tender a disminuir, por un trabajo más coordinado e integrado entre sectores, redes público-privadas y decisores regionales y locales, que permitiría facilitar los procesos de decisión.

\section{LIDERAZGO}

口 Se otorga una alta importancia a los liderazgos políticos, dejando entrever que el éxito del sistema depende en gran medida de la capacidad de conducción de las autoridades unipersonales del nivel comunal y regional. Por el contrario, se tiende a desestimar el rol de la autoridad provincial.

口 Algunos actores perciben que la alta dependencia de los liderazgos personales es riesgosa, porque el sistema de gestión puede durar lo que ciertas personas duren en sus cargos. Sin embargo, la mayoría confía en los liderazgos y no cuestiona la falta de institucionalización de los estilos de gestión que implementan tales liderazgos.

口 Se reconoce y valora positivamente el fuerte liderazgo del actual intendente, quien se relaciona directamente con los alcaldes y concejales de las distintas comunas de la región.

口 El hecho de que la gestión de esta región se caracterice por el reconocimiento del liderazgo político por sobre otros tipos de liderazgos, tiene ventajas y desventajas. Las ventajas están determinadas por las características personales del intendente. Si es un líder competente política y profesionalmente, y además es carismático con visión de futuro, el sistema de gestión regional se fortalece. Las desventajas están determinadas justamente si ocurre lo contrario de la ventaja. Por tanto, el resultado puede ser indeterminado. 


\section{Confianza}

a En todos los niveles se manifiesta que existe confianza entre las distintas entidades que participan en el sistema de gestión de la región.

․ Se enfatiza la existencia de confianzas políticas más que técnicas, si bien se afirma que las confianzas se han profundizado producto de la nueva gestión del Gore, que ha tendido a profundizar y clarificar los procedimientos técnicos, como también a transparentar la información y las acciones, y a establecer estilos de gestión orientados a una mejora en el clima organizacional.

口 En el nivel comunal se señala la influencia de factores políticos como aspectos que inciden negativamente en la confianza. Además, los actores comunales perciben que existe menor confianza que los actores regionales.

a Se desprende la necesidad de fortalecer las acciones colectivas de los distintos actores que intervienen en el sistema de gestión regional. La confianza en el liderazgo debe ser apoyada por el fortalecimiento de la capacidad técnica de gestión. Para esto se debe elaborar un inventario de las competencias profesionales que mantienen al sistema y determinar las brechas de competencia para el desempeño de sus funciones, para luego intervenir sobre ellas, formando y especializando al personal.

\section{Participación}

\section{PARTicipación INSTITUCIONAL}

[ En todos lo niveles, los actores coinciden en que la participación institucional se expresa a través del Gore y los municipios, en sus dimensiones políticas y técnicas.

․ Coinciden también en que la participación de los Cores es limitada, pero no existe una visión sobre cómo puede ampliarse tal participación, de manera tal que constituya más que una mera formalidad.

- En el nivel comunal se enfatiza la necesidad de tener una mayor participación del Gore, en cuanto apoyo técnico a la unidad técnica del municipio.

口 Las acciones más pertinentes que se deben ser desarrolladas son: fortalecer las acciones de coordinación territorial entre las distintas instancias, a sa- 
ber, comuna, provincia, región; fortalecer las acciones de coordinación y articulación intersectorial en el gabinete regional ampliado; y favorecer la participación de los municipios en sus ejes territoriales, mediante la coordinación de los alcaldes, concejales y consejeros regionales con el ejecutivo regional.

\section{PARTICIPACIÓN DE LAS ORgANIZACIONES SOCIALES Y POLÍTICAS}

口 En todos los niveles existe consenso respecto de que la participación de las organizaciones sociales y políticas en el sistema de gestión es nula o inexistente.

u En el nivel regional político se tiende a pensar que este tipo de participación es más propia del nivel comunal que del nivel regional. En el nivel regional técnico, por contraste, se le otorga un espacio en la región.

u En el nivel comunal se enfatiza la falta de participación en el proceso desarrollado por el municipio.

u Existen diferentes formas de ver la participación: involucramiento de las organizaciones sociales en proyectos determinados; participación en la priorización de los proyectos; participación en la aprobación de cada proyecto. Si bien estas instancias no son excluyentes y se debiera tender a la inclusión de todas ellas, el análisis revela que los actores coinciden en la falta de participación en el proceso, pero no coinciden en cuál es el rol que la ciudadanía u organizaciones sociales debieran tener en el proceso. Las estrategias para fomentar el sistema de gestión en esta región debieran considerar instancias de discusión para que los actores puedan reflexionar respecto de las formas de participación posibles y las medidas deben tomar para alcanzarla.

\section{Componente institucional}

\section{CONOCIMIENTO Y APLiCACIÓN DE NORMAS E INSTRUMENTOS}

a Los actores conocen, en general, la existencia de instrumentos jurídicos del sistema de gestión. Sin embargo, en su mayoría no identifican espontáneamente el Instructivo Presidencial no 155.

a Se entiende el Pladeco y EDR como instrumentos normativos más que como instrumentos para la gestión, lo que dificulta que estos instrumentos sean 
incorporados como herramientas para la implementación del sistema de gestión. Sin embargo, la reciente formulación del Pladeco en la comuna de Caldera representa una oportunidad para incorporarlo, hecho que es reconocido por los actores comunales.

口 El análisis revela que existen bajos niveles de discusión y preparación técnica sobre instrumentos y funcionamiento del sistema de gestión regional.

Particularidades Del Modelo

[ Aunque algunos actores identifican ciertos elementos que distinguen su sistema de gestión respecto de otras regiones o comunas, la mayoría tiene dificultades para identificar tales elementos. Los elementos identificados son más bien propios de la definición del sistema de gestión, que de su implementación en esta región.

a Existe cierta tendencia a manifestar que la nueva gestión del intendente imprimirá un sello distintivo en la región, lo que ratifica que hasta ahora no han visto elementos distintivos.

口 El análisis revela dificultades en la institucionalización del sistema, pues los actores no logran identificarse con un sistema propio. También, indica que existen deficiencias en las competencias técnicas, pues entregan escasas referencias a lo que ocurre en otras regiones o comunas. Todo esto señala la necesidad de evaluar las competencias técnicas en los distintos niveles y realizar la capacitación que dicha evaluación indique.

\section{Referências bibliográficas}

BOBBIO, N. et al. Diccionario de política. Madrid: Siglo XXI, 1999.

CASTELLS, M. La era de la información. Economía, sociedad y cultura. La sociedad red. Madrid: Siglo XXI, 1999.

CUNILL, N. Repensando lo público a través de la sociedad. Nuevas formas de gestión pública y representación social. Caracas: Clad/Nueva Sociedad, 1997.

HELD, D. Modelos de democracia. Madrid: Alianza Universidad, 1993.

LECHNER, N. El ciudadano y la noción de lo público. In: Leviatán: Revista de Hechos e Ideas, Madrid, n. 43-44, 1991. 
MARINI, C.; MARTINS, H. Um goberno matricial: estruturas em rede para gereção de resultados de desenvolvimento. In: CONGRESO INTERNACIONAL DEL CLAD, 9., 2004, Madrid. Anales... Madrid, 2004.

MARTINS, H. Introdução ao governo matricial: o problema da fragmentação. In: CONGRESO INTERNACIONAL DEL CLAD, 9., 2004, Madrid. Anales... Madrid, 2004.

MINTZBERG, H. Diseño de organizaciones eficientes. Buenos Aires: El Ateneo, 1991.

MOUFFE, C. El retorno de lo político. Comunidad, ciudadanía, pluralismo, democracia radical. Buenos Aires: Paidos, 1992.

MUÑOZ, O. El desarrollo tecnológico como objetivo estratégico. In: (Editor). Políticas públicas para un desarrollo competitivo. Santiago de Chile: Universidad de Santiago/ Instituto de Estudios Avanzados, 1997.

PALMA, D. Las dificultades y desafíos de la descentralización. In: SALAZAR, G.; BENITEZ, J. (Compiladores). Autonomía, espacio y gestión. El municipio cercenado. Santiago de Chile: LOM, 1997. Colección Sin Norte, Serie Punto de Fuga.

PARSONS, T. El sistema social. Madrid: Ediciones de la Revista de Occidente, Biblioteca de Política y Sociología, 1966.

PETERS, G. La política de la burocracia. Ciudad de México: Fondo de Cultura Económica, 1999.

PUTNAM, R. Para hacer que la democracia funcione: la experiencia italiana en descentralización administrativa. Caracas: Galac, 1994.

RACZYNSKI, D.; SERRANO, C. Descentralización: nudos críticos. Santiago de Chile: Cieplan, Asesorías para el Desarrollo, 2001.

ROVERSI-MONACO, F. Descentralización. In: BOBBIO, N. et al. Diccionario de política. 11. ed. Coyoacan: Siglo XXI, 1998.

SUBDERE (Subsecretaría de Desarrollo Regional y Administrativo). El Chile Descentralizado que Queremos, un proyecto de todos. Santiago de Chile: Subdere, 2001.

. Algunos criterios para la definición de las competencias de los niveles nacional, regional $\bar{y}$ local de la administración del Estado. Santiago, 2003. Serie de Estudios, n. 4.

. Fuentes de recursos para el desarrollo regional y local. Santiago, 2004. Documento de trabajo n. 30 .

WEBER, M. Economía y sociedad. Ciudad de México: Fondo de Cultura Económica, 1997.

ZIMMERMAN, J. Democracia participativa: el resurgimiento del populismo. Ciudad de México: Limusa/Grupo Noriega, 1992. 